\title{
Tension-stiffening model for FRC reinforced by hybrid FRP and steel
}

\author{
bars \\ Hadi Mazaheripour ${ }^{1}$, Joaquim Barros², Jose Sena-Cruz ${ }^{3}$
}

\begin{abstract}
This paper presents a tension stiffening model for Fiber Reinforced Concrete (FRC) tensile member reinforced by hybrid glass fiber reinforced polymer (GFRP) and steel bars. The model is developed through an explicit analytical bond formulation by considering a four-linear bond shear stress-slip relationship to simulate the bond behavior between reinforcing bars and surrounding FRC. The model is also capable of simulating both the fiber reinforcement contribution and the yielding stage of steel bar at cracked section. Additionally, a FE Model is carried out using a multi-directional smeared crack approach for modeling cracking process in FRC, and adopting interface finite elements to simulate the bond behavior between reinforcements and FRC, whose constitutive model was defined from the aforementioned bond law. Both the analytical and numerical approaches showed a good agreement with some recent experimental results on tension-stiffening in the literature. Finally, an extensive parametric study is performed by using the analytical model, and the influence of the involved parameters on the tension-stiffening and cracking behavior of hybrid GFRP/steel FRC tensile member is investigated.
\end{abstract}

Keywords: Tension-Stiffening, FRP and Steel bars, FRC, analytical model, FEA

1 ISISE, PhD student, Dep. of Civil Engineering, University of Minho, 4800-058 Guimarães, Portugal. h.mazaheripour@gmail.com

2 ISISE, Full Professor, Dep. of Civil Engineering, University of Minho, 4800-058 Guimarães, Portugal. barros@civil.uminho.pt.

${ }^{3}$ ISISE, Associate Professor, Dep. of Civil Engineering, University of Minho, 4800-058 Guimarães, Portugal. jsena@civil.uminho.pt. 


\section{INTRODUCTION}

For the last two decades, the use of Glass Fiber Reinforced Polymer (GFRP) bars as internal reinforcements for concrete has been significantly increased, mostly for those Reinforced Concrete (RC) structures that are exposed to aggressive environments. However, the relatively low axial stiffness of GFRP bars, as well as theirdifferent bond-slip behavior of GFRP-concrete interface $[1,2]$ when compared with steel-concrete interface, usually result in higher deformability and crack width at serviceability load conditions. Hence, a deeper attention in predicting and designing GFRP-RC members is needed. Many studies have already been carried out to investigate the structural behavior of GFRP Reinforced Concrete (GFRP-RC) members, e.g.[3-5] and also several countries have already published codes and design guidelines including ACI [6], JSCE [7], FIB [8] and CSA [9] for FRP reinforced concrete members. However, the brittle failure behavior of GFRP bars, and the lower structural performance under service loads compared with conventional steel bars are still concerns on the adoption of GFRP reinforcements in many structural applications. To this end, GFRP-RC beams are usually over-reinforced in such way that concrete crushing in compression zone governs the failure mode. Additionally, GFRP bars are susceptible to fire.

Combining GFRP and steel bars as hybrid flexural reinforcing system seems to be a promising solution to overcome such problems. In this hybrid system, steel reinforcement ratio is designed to assure safety and integrity requirements in case of fire as well as to enhance the structural performance in terms of crack width, deformability and ductility. To improve durability, these longitudinal steel bars are placed in the tensile region of the member with relatively larger concrete cover for being better protected from corrosion. Due to the corrosion immunity of GFRP bars, a minimum concrete cover is used in order to assure proper transmission of bond forces and maximize the inner lever arm formed by GFRP bars and concrete under compression. Some research has already been carried out where GFRP and steel bars are combined [10-12], and it is reported an improvement in the flexural behavior when comparing with GFRP-RC solutions.

In addition, steel stirrups are the reinforcing system more succepible to corrosion since they are closer to the exposed surfaces of concrete elements. For eliminating steel stirrups, using a High-Performance Fiber Reinforced Concrete (HPFRC) might be a solution, as long as this material provides similar shear reinforcement effectiveness $[13,14]$. Due to the quite high post-cracking tensile strength and energy absorption capacity that HPFRC can 
attain, this composite can be used not only to assure the required shear capacity to RC elements, but also to enhance the structural performance at serviceability and ultimate limit states (SLS and ULS, respectively) [13, 14]. In the context of this research topic, a study on the interaction between Fiber Reinforced Concrete (FRC), GFRP and steel bars seems to be essential for a reliable prediction of the behavior of hybrid FRC members. For this purpose, a FRC member reinforced with GFRP and steel bars (hybrid reinforcement) is subjected to uniaxial tension, and its cracking and tension stiffening behavior is theoretically studied. Some researchers have already investigated the tension stiffening of conventional Steel-FRC structures [15-17], and more recently some studies have been done with GFRP-RC [18-21]. Most of them have focused on the results obtained experimentally by subjecting a concrete member to uniaxial tension test. Some theoretical approaches have been developed for predicting the tension stiffening behavior of GFRP-RC $[22,23]$ and S-FRC $[16,24,25]$. However, according to the knowledge of the athours, there is no research on cracking analysis and tension stiffening effect of hybrid FRPsteel reinforced FRC structures.

By using a local bond-slip law for modeling the bond behavior between FRC and FRP/Steel bar reinforcement, an analytical model is developed in the present work through an explicit formulation. This model is then validated by using some recent experimental data available in the literature. However, since there is no experimental results available for tension stiffening of hybrid FRP/Steel FRC tensile member, a finite element (FE) model using interface elements [26] is employed, and the results from the numerical simulations are compared with those obtained from the analytical model. A parametric study is also carried out by using the proposed analytical approach, and the effectiveness of the model parameters in terms of cracking and tension-stiffening behavior of hybrid FRP/Steel FRC is assessed. 


\section{ANALYTICAL MODEL}

A FRC member is considered to be reinforced with a constant reinforcement ratio of FRP and steel bars along its longitudinal axis, which is subjected to uniaxial tension load in order to analyze the tension-stiffening effect and its cracking behavior. To prevent bending effects in the member, symmetric arrangement of the reinforcements is assumed in the FRC cross-section.

\subsection{Crack formation stage}

When the load is applied to the member, it is transmitted to the FRC throughout a part of embedded length of reinforcing bar in which the total bond shear force over this distance is in static balance with the applied load. This part of embedded length can be named as transferred bond length $\left(L_{t r}\right)$, which depends on the bond mechanism between the reinforcing bars and surrounding FRC [27]. The part of the member beyond the $L_{t r}$ behaves as a real composite element ("tie region" in Figure 1), where the slip ( $\delta$ ) between the bars and surrounding FRC is null and the total applied force is shared between them in accordance with their axial stiffness. Since the total applied load is transferred throughout two different $L_{t r}$ that belong to FRP and steel bars, the higher $L_{t r}$ is adopted to calculate the tie region.

As long as the FRC tensile stress in the tie region is less than its tensile strength, $f_{c t}$, the member remains uncracked. At this stage, the fibers are almost inactive. Once $f_{c t}$ is reached in the tie region, a crack is formed over the weakest section (It is assumed that this section distanced $L_{c r}$ from the specimen's extremity, see Figure 1). At this cracked section, the tensile stress of concrete matrix tends to drop to zero with the crack opening, while the tensile stresses in the bars and discrete fibers, which are now active, tend to increase. By increasing the tensile stresses in the reinforcements, the reinforcing bars and fibers start slipping out from the surrounding concrete matrix, leading to an increase of the crack width. The total force is redistributed to the concrete, and if once again the tensile strength is reached, a second crack is formed. At this stage, the force transferred by fibers at the first cracked section also contributes to the formation of the second crack. This process, which named "crackformation stage” [28], continues until all cracks are formed along the member and no tie region exists anymore. 


\subsection{Bond formulation and bond-slip law of the reinforcing bars}

An infinitesimal length $d x$ of the tensile member at a distance $x$ (see Figure 1) is shown in Figure 2. The equilibrium of this element can be expressed by

$$
\begin{gathered}
\frac{d \sigma_{s}(x)}{d x}=\frac{P_{s}}{A_{s}} \tau_{s}(x) \\
\frac{d \sigma_{F}(x)}{d x}=\frac{P_{F}}{A_{F}} \tau_{F}(x) \\
\left(\frac{d \sigma_{c}(x)}{d x}+\frac{d \sigma_{c f}(x)}{d x}\right)=-\left(\frac{P_{F}}{A_{c}} \tau_{F}(x)+\frac{P_{s}}{A_{c}} \tau_{s}(x)\right)
\end{gathered}
$$

and also

$$
\left(\sigma_{c}(x)+\sigma_{c f}(x)\right) A_{c}+\sigma_{F}(x) A_{F}+\sigma_{s}(x) A_{s}=F
$$

where $\sigma_{c f}$ is the local tensile stress of concrete due to the force transferred to the concrete matrix by the steel fibers at cracked section in the member. $\sigma_{c}, \sigma_{s}$ and $\sigma_{F}$ are the tensile stress of concrete matrix, steel bar and FRP bar, respectively. Hereafter, subscript " $s$ " is used to designate parameters for steel bar, while " $F$ " is for FRP bar. The perimeter of the steel and FRP bars is designated by $P_{s}$ and $P_{F}$, respectively, while the cross sectional area of these bars is $A_{s}$ and $A_{F} \cdot E_{c} A_{c}$ is the concrete axial stiffness.

The slip ( $\delta$ ) between the reinforcements and FRC is defined by Eq. (5) and (6) for steel and FRP bar, respectively.

$$
\begin{gathered}
\delta_{s}(x)=u_{s}(x)-u_{c}(x) \Rightarrow \frac{d \delta_{s}(x)}{d x}=\varepsilon_{s}(x)-\varepsilon_{c}(x) \Rightarrow \frac{d^{2} \delta_{s}(x)}{d x^{2}}=\frac{d \varepsilon_{s}(x)}{d x}-\frac{d \varepsilon_{c}(x)}{d x} \\
\delta_{F}(x)=u_{F}(x)-u_{c}(x) \Rightarrow \frac{d \delta_{F}(x)}{d x}=\varepsilon_{F}(x)-\varepsilon_{c}(x) \Rightarrow \frac{d^{2} \delta_{F}(x)}{d x^{2}}=\frac{d \varepsilon_{F}(x)}{d x}-\frac{d \varepsilon_{c}(x)}{d x}
\end{gathered}
$$

where $u$ and $\varepsilon$ represent elongation and strain, respectively. By substituting Eq. (1) and (3) into Eq. (5) and also Eq. (2) and (3) into Eq. (6) yield the following set of nonlinear differential equations governing the bond problem of the member:

$$
\left\{\begin{array}{l}
\frac{d^{2} \delta_{s}(x)}{d x^{2}}=\frac{P_{s}}{E_{s} A_{s}}\left(1+\mathrm{n}_{s} \rho_{s}\right) \tau_{s}(x)+\frac{P_{F}}{E_{c} A_{c}} \tau_{F}(x)+\frac{1}{E_{c}} \frac{d \sigma_{c f}}{d x} \\
\frac{d^{2} \delta_{F}(x)}{d x^{2}}=\frac{P_{F}}{E_{F} A_{F}}\left(1+\mathrm{n}_{F} \rho_{F}\right) \tau_{F}(x)+\frac{P_{s}}{E_{c} A_{c}} \tau_{s}(x)+\frac{1}{E_{c}} \frac{d \sigma_{c f}}{d x}
\end{array}\right.
$$


where $n$ is the modular ratio $\left(n_{s}=E_{s} / E_{c}, n_{F}=E_{F} / E_{c}\right)$, and $\rho$ is the reinforcement ratio $\left(\rho_{s}=A_{s} / A_{c}\right.$, $\rho_{F}=A_{F} / A_{c}$ ). It should be noticed that the materials are assumed to follow the Hook's constitutive law. Moreover, in the equilibrium conditions expressed in Eqs. (1) to (3), the resisting tensile stress due to the concrete softening at cracked section is neglected since this value drops asymptotically to zero for a very small slip of the reinforcements [29].

To simplify the complexity of solving the set of second-order nonlinear differential equations presented in Eqs. (7) , the elastic deformation of surrounding concrete matrix is neglected against the reinforcement's deformation at the interface (i.e. $u_{s}>>u_{c}$ and $u_{F}>>u_{c}$ ). By this assumption, Eqs. (5) and (6) become

$$
\frac{d^{2} \delta_{s}(x)}{d x^{2}}=\frac{d \varepsilon_{s}(x)}{d x}, \quad \frac{d^{2} \delta_{F}(x)}{d x^{2}}=\frac{d \varepsilon_{F}(x)}{d x}
$$

Hence, Eq. (7) is derived as

$$
\left\{\begin{array}{l}
\frac{d^{2} \delta_{s}(x)}{d x^{2}}=J_{s} \tau_{s}(x) \\
\frac{d^{2} \delta_{F}(x)}{d x^{2}}=J_{F} \tau_{F}(x)
\end{array}\right.
$$

where

$$
\left\{\begin{array}{l}
J_{s}=\frac{P_{s}}{E_{s} A_{s}}\left(1+\mathrm{n}_{s} \rho_{s}\right) \\
J_{F}=\frac{P_{F}}{E_{F} A_{F}}\left(1+\mathrm{n}_{F} \rho_{F}\right)
\end{array}\right.
$$

Depending on the bond-slip relationship between reinforcing bar and concrete, Eqs. (9) can be solved explicitly or by using a numerical procedure [30]. There are several bond-slip constitutive laws in the literature that have been proposed for FRP reinforcing bars, namely Malvar Model [31], mBEP Model, CMR Model [32], the model proposed by Model Code 2010 [28], and etc. In all these models, nonlinear formula has been adopted for the first branch of the constitutive law. Thus, by substituting any of these models in Eq. (9), it does not lead to an explicit solution. Then, numerical procedure is required to solve the equation. From this standpoint, a multi-linear bondslip diagram, consisting of two linear ascending branches prior to the peak bond shear stress, is adopted in the present study to solve Eq. (9) for both steel and FRP bars. This multi-linear bond-slip diagram is shown in Figure $3 \mathrm{a}$, and is mathematically represented by the following equation: 


$$
\tau(\delta)= \begin{cases}\tau_{0}+\frac{\tau_{1}-\tau_{0}}{\delta_{1}} \cdot \delta & 0 \leq \delta \leq \delta_{1} \\ \tau_{1}+\frac{\tau_{m}-\tau_{1}}{\delta_{2}-\delta_{1}} \cdot\left(\delta-\delta_{1}\right) & \delta_{1}<\delta \leq \delta_{2} \\ \tau_{m} & \delta_{2}<\delta \leq \delta_{3} \\ \tau_{m}-\frac{\tau_{m}-\tau_{R}}{\delta_{4}-\delta_{3}} \cdot\left(\delta-\delta_{3}\right) & \delta_{3}<\delta \leq \delta_{4} \\ \tau_{R} & \delta>\delta_{4}\end{cases}
$$

\subsection{Contribution of discrete fibers}

Once the crack formed, the fibers start pulling out from the crack plane with increase in crack width. In order to calculate the force transferred by these discrete fibers at the cracked plane, two methods can be used according to the data available for modeling the fiber reinforcement contribution. If the fiber bond-slip behavior is known, the following equations represent the bond problem formulation of each fiber at cracked plane:

$$
\left\{\begin{array}{l}
\frac{d^{2} \delta_{f r}}{d x_{f r}^{2}}=\frac{P_{f r}}{E_{f r} A_{f r}} \tau_{f r}\left(\delta_{f r}\right) \\
\varepsilon_{f r}=\frac{d \delta_{f r}}{d x_{f r}}
\end{array}\right.
$$

where the subscript " $f r$ " designates the parameters for discrete fibers with the same concepts as defined previously for reinforcing bars. $x_{f r}$ origins at the extremity of the effective bond length of a fiber crossed by the cracked plane (see Figure 4a). According to the literature, this fiber effective bond length is statistically considered 0.25 of total length $[33,34]$, leading to pulled out of fiber at one side of the cracked plane (i.e. $\delta_{f r}=w_{c r}$ ), therefore, Eq. (12) can be solved by the following boundary conditions

$$
\left\{\begin{array}{l}
\frac{d \delta_{f r}}{d x}\left(x_{f r}=0\right)=\varepsilon_{f r}\left(x_{f r}=0\right)=0 \\
\delta_{f r}\left(x_{f r}=0.25 l_{f r}\right)=w_{c r}
\end{array}\right.
$$

where $l_{f r}$ is the fiber length and $w_{c r}$ is the crack width. Based on what bond-slip constitutive law is adopted for fiber, Eq. (12) can have an explicit solution, or a numerical procedure is required (e.g. Runge-Kutta-Nystrom method [35]). Cunha et al. in 2010 presented different bond-slip constitutive laws for steel fibers depending on the angle between fibers and crack plane they are crossing, as well as the type of steel fibers [36]. Therefore, by 
adopting a proper bond-slip law, the pullout force of steel fibers can be calculated using the analytical model proposed by these authors. Lee et al. in 2011 [37] developed a model named "Diverse Embedment Model (DEM)" to calculate the tensile behavior of FRC by considering the pullout characteristics of fibers, as well as the effective orientation of fibers in regards to the crack plane. Abrishambaf et al. [38] also compared different post-cracking response of steel fiber Reinforced Self-Compacting Concrete (SFRSCC) by taking into account fiber's orientation towards the crack plane. Once the pullout force of each fiber is calculated, the total force of fibers can be determined by considering an average number of fibers at cracked section in accordance with their volume friction in concrete mix.

On the other hand, if the uniaxial behavior of FRC in tension is known, the contribution of fibers may be measured alternatively by subtracting the tension softening diagram of concrete from the post-cracking diagram of FRC. The tension softening diagram of concrete can be estimated according to the CEB-FIB Model Code 2010 [28] or from available experimental data [28], by considering the effective length equal to distance between two cracks. This concept is shown in Figure 4b. In the present study, the contribution of fibers is calculated based on the average post-cracking response of FRC, which can be obtained by performing uniaxial tensile tests or from inverse analysis considering the results recorded in three point notched beam bending tests $[39,40]$. Therefore, the total force transferred to the concrete matrix by fibers is calculated by

$$
\left(V_{c}\right)_{f r}=\sigma_{c t}^{c r}\left(w_{c r}\right) \cdot A_{c}
$$

where $\sigma_{c t}^{c r}$ is the concrete crack tensile stress as function of crack width, $w_{c r}$.

\subsection{Bond boundary conditions and solutions for reinforcing bars}

Bond mechanism of a reinforcing bar crossed by two consecutive cracks can be analyzed solving Eq. (9) using boundary condition as follow:

$$
\begin{cases}x=0, & \delta_{r}=0 \\ x=L_{b}, & \delta_{r}=\delta_{c r}\end{cases}
$$

where $x$ origins from the midway section between two consecutive cracks, $L_{b}$ is the bond length that is equal to $L_{c r} / 2$ being $L_{c r}$ the distance between two cracks, and $\delta_{c r}$ is the slip at crack section. Based on Eq. (5) and (6), the 
strain of reinforcing bars at the midway section is equal to the derivation of the slip at this point (i.e. $\varepsilon_{r}^{m}=\frac{d \delta(x=0)}{d x}$ ). The total force that is transferred to the concrete matrix by the reinforcing bars is calculated using the difference of the tensile strain of reinforcing bars at cracked section (i.e. $\varepsilon_{r}^{c r}=\frac{d \delta\left(x=L_{b}\right)}{d x}$ ) and at midway section, multiplying by the reinforcing bar's axial stiffness:

$$
\left(V_{c}\right)_{r}=E_{r} A_{r}\left(\varepsilon_{r}^{c r}-\varepsilon_{r}^{m}\right)
$$

where $\left(V_{c}\right)_{r}$ is the total force transferred to the surrounding concrete matrix due to the bond action of reinforcing bars. Note that the subscript " $r$ " represents parameters for both reinforcing bars, FRP and steel bars.

During the "crack formation stage", where the tie region exists in the member, bond mechanism at one side of the last formed crack (designated by letter "R" meaning right side) undergoes "Infinite Bond Length" (IBL) boundary conditions (see Figure 5). IBL represents a bond boundary condition where the $L_{t r}$ increases with the pullout force in which the slip and its derivative at the extremity of $L_{t r}$ are always null (i.e. $\left.\delta\left(x_{R}=0\right)=0, \frac{d \delta\left(x_{R}=0\right)}{d x_{R}}=0\right)$. On the other hand, another side of the last formed crack (designated by letter "L" meaning left side) undergoes "Finite Bond Length" (FBL) boundary conditions. FBL represents bond boundary condition where the transferred bond length ( $L_{t r}$ ) equals to a finite bond length (for case of this study $L_{b}=L_{c r} / 2$ ) and slip at the extremity of this bond length is null, while its derivative is not null (i.e. $\left.\delta\left(x_{L}=0\right)=0, \frac{d \delta\left(x_{L}=0\right)}{d x_{L}} \neq 0\right)$. Under this consideration, at the last formed cracked plane two bond conditions govern the bond formulation, where the slips on left and right sides of this crack are not necessarily equal (Figure 5), and, therefore, Eqs. (9) is solved by using the following boundary conditions

$$
F B L\left\{\begin{array} { l } 
{ \delta ( x _ { L } = 0 ) = 0 } \\
{ \delta ( x _ { L } = L _ { b } ) = ( \delta _ { c r } ) ^ { L e f t } }
\end{array} \quad I B L \left\{\begin{array}{l}
\delta\left(x_{R}=0\right)=0 \\
\delta\left(x_{R}=L_{t r}\right)=\left(\delta_{c r}\right)^{\text {Right }}
\end{array}\right.\right.
$$

where $x_{R}$ has its origin at section $B$, and $x_{L}$ at section A. The slip at left $\left(\delta_{c r}\right)^{\text {Left }}$ and right side $\left(\delta_{c r}\right)^{\text {Right }}$ of the last formed crack is not necessarily equal, but due to the compatibility of strain at this section, the derivatives of the slip at right and left are equal to the reinforcing bar's strain, i.e. $\varepsilon_{r}^{c r}$ 


$$
\varepsilon_{r}^{c r}=\left(\frac{d \delta}{d x_{R}}\right)_{R i g h t}=\left(\frac{d \delta}{d x_{L}}\right)_{\text {Left }}
$$

By solving Eq. (9) using FBL and IBL boundary conditions, for whatever value of $\delta_{c r}$, slip distribution, $\delta(x)$, reinforcing bar's tensile strain, $\varepsilon_{r}(x)$, and bond shear stress, $\tau(x)$, as well as the force transferred to concrete by the bond action, $\left(V_{c}(\mathrm{x})\right)_{r}$, are calculated throughout crack spacing $\left(L_{c r}\right)$, as will be explained in the following sections.

The formulations for IBL conditions and its solving procedures are described in detail elsewhere [27], while, the formulation for FBL conditions is summarized hereafter.

According to the adopted bond-slip law, see Figure 3a, five different bond phases are considered during debonding progress, namely:

1) Elastic phase (e): $\delta_{c r} \leq \delta_{1}$;

2) Hardening phase $(h): \delta_{1}<\delta_{c r} \leq \delta_{2}$;

3) Plastic phase (p): $\delta_{2}<\delta_{c r} \leq \delta_{3}$;

4) Softening phase (so): $\delta_{3}<\delta_{c r} \leq \delta_{4}$;

5) Frictional phase $(f)$ : $\delta_{c r}>\delta_{4}$.

Based on these five bond-slip phases, substituting Eq. (11) into Eq. (9), and taking FBL boundary conditions indicated in Eq. (18), the closed-form solution of Eq. (9) for each reinforcing bar can be expressed by

$$
\delta(x)=\left\{\begin{array}{l}
\delta\left(x_{e}\right)=C_{1} e^{\lambda_{1} x_{e}}+C_{2} e^{-\lambda_{1} x_{e}}-C_{e} ; \quad 0 \leq x_{e} \leq L_{t r}^{e} \\
\delta\left(x_{h}\right)=C_{3} e^{\lambda_{2} x_{h}}+C_{4} e^{-\lambda_{2} x_{h}}-C_{h}+\delta_{2} ; \quad 0 \leq x_{h} \leq L_{t r}^{h} \\
\delta\left(x_{p}\right)=C_{p} x_{p}{ }^{2}+C_{5} x_{p}+\mathrm{C}_{6} ; \quad 0 \leq x_{p} \leq L_{t r}^{p} \\
\delta\left(x_{s o}\right)=C_{7} \sin \left(\gamma x_{s o}\right)+C_{8} \cos \left(\gamma x_{s o}\right)+C_{s o}+\delta_{3} ; \quad 0 \leq x_{s o} \leq L_{t r}^{s o} \\
\delta\left(x_{f}\right)=\mathrm{C}_{f} x_{f}{ }^{2}+\mathrm{C}_{9} x_{f}+\mathrm{C}_{10} ; \quad 0 \leq x_{f} \leq L_{t r}^{f}
\end{array}\right.
$$

where the definition of $x_{e}, x_{h}, x_{p}, x_{s o}, x_{f}, L_{t r}^{e}, L_{t r}^{h}, L_{t r}^{p}, L_{t r}^{s o}$, and $L_{t r}^{f}$ can be found in Appendix A, as well as how the $C_{e}, C_{h}, C_{p}, C_{s o}$ and $C_{f}$ constant parameters are determined. The slip solutions $C_{1}$ to $C_{10}$ are obtained for whatever value of $\delta_{c r}$ and the transferred bond length of each bond phases (i.e. $L_{t r}^{e}, L_{t r}^{h}, L_{t r}^{p}, L_{t r}^{s}$ and $L_{t r}^{f}$ ). 
By considering the compatibility conditions of the strain at the connection point of two consecutive bond phases (found in Appendix A), as well as the following conditions of the bond length $\left(L_{b}=\frac{1}{2} L_{c r}\right)$ with respect to the different stages of $\delta_{c r}$, the values of $L_{t r}^{e 1}, L_{t r}^{e 2}, L_{t r}^{p}, L_{t r}^{s o}$ and $L_{t r}^{f}$ are calculated for whatever value of $\delta_{c r}$. Therefore, by imposing $\delta_{c r}$, theses transferred bond lengths and the slip solutions (i.e. $C_{1}$ to $C_{10}$ ) are found.

- Stage $1\left(0<\delta_{c r} \leq \delta_{1}\right)$ : the total bond length undergoes only the elastic bond phase, i.e. $L_{b}=L_{t r}^{e}$;

- Stage $2\left(\delta_{1}<\delta_{c r} \leq \delta_{2}\right)$ : the total bond length undergoes the elastic and hardening bond phases, i.e. $L_{b}=L_{t r}^{e}+L_{t r}^{h}$

- Stage $3\left(\delta_{2}<\delta_{c r} \leq \delta_{3}\right)$ : the total bond length undergoes elastic, hardening and plastic bond phases, i.e. $L_{b}=L_{t r}^{e}+L_{t r}^{h}+L_{t r}^{p}$

- Stage $4\left(\delta_{3}<\delta_{c r} \leq \delta_{4}\right)$ : the total bond length undergoes elastic, hardening, plastic and softening bond phases, i.e. $L_{b}=L_{t r}^{e}+L_{t r}^{h}+L_{t r}^{p}+L_{t r}^{s o}$;

- Stage $5\left(\delta_{c r}>\delta_{4}\right)$ : the total bond length undergoes all the bond phases, i.e. $L_{b}=L_{t r}^{e}+L_{t r}^{h}+L_{t r}^{p}+L_{t r}^{s o}+L_{t r}^{f}$. If the compatibility conditions of the strain at the connection point of two consecutive bond phases (e.g. elastichardening or hardening-plastic) are considered, the values of $L_{t r}^{e 1}, L_{t r}^{e 2}, L_{t r}^{p}, L_{t r}^{s o}$ and $L_{t r}^{f}$ can be calculated for whatever value of $\delta_{c r}$. The compatibility conditions of each solving stage are included in Appendix A.

By imposing a value of $\delta_{c r}$ and using the above compatibility conditions, the transferred bond lengths, as well as the slip solutions (i.e. $C_{1}$ to $\left.C_{10}\right)$ are found. Once $\delta(x)$ is found, the distribution of tensile strain in the reinforcing bars and also the bond shear stress are given by

$$
\left\{\begin{array}{l}
\varepsilon_{r}(x)=E_{r} \frac{d \delta(x)}{d x} \\
\tau(x)=\frac{1}{J_{r}} \frac{d^{2} \delta(x)}{d x^{2}}
\end{array}\right.
$$

where $J_{r}$ is defined in Eq. (10) for both FRP and steel bars, and $E_{r}$ is the elasticity modulus of reinforcing bar. The solving procedure of Eq. (9) under FBL boundary conditions, and the respective formulations, as well as the flowchart of the FBL algorithm are given in detail in Appendix A. 


\subsection{Secondary crack formation stage}

Once all the cracks are formed at "crack formation stage", by increasing the slips at cracked sections, the tensile strains of reinforcement at crack, $\varepsilon_{r}^{c r}$, and midway section, $\varepsilon_{r}^{m}$, increase. Note that, at this stage no "tie region" exists in the member, and only FBL boundary conditions govern the bond formulation. The total value of the force transferred to the concrete matrix by the bond mechanism of the reinforcements (both reinforcing bars and fibers) is estimated by

$$
\left(V_{c}\right)_{t}=\left(V_{c}\right)_{r}+\left(V_{c}\right)_{f r}
$$

where $\left(V_{c}\right)_{f r}$ is the total force transferred to the concrete matrix by fibers, which is calculated by Eq. (14). In this equation, the value of crack opening, $w_{c r}$, is estimated as double value of reinforcing bar's slip at cracked section due to the symmetric bond action [41], which means:

$$
w_{c r}=2 \delta_{c r}
$$

If the value of $\left(V_{c}\right)_{t}$ reaches the concrete cracking force, $V_{c r}=f_{c t} \cdot A_{c}$, a new crack is formed in the midway section between two consecutive cracks (e.g. section A in Figure 5). The bond length associated to this new crack is $L_{c r} / 4$ , and the symmetric section between two cracks is now changed from section A to C (see Figure 5). This stage can be named as "secondary crack formation stage".

\subsection{Updating bond-slip constitutive law during the analysis}

The proposed local bond-slip constitutive law is valid while the slip is increasing. If the slip at a local point of interface tends to decrease, $\tau=\delta$ follows an "unloading" branch. If the slip at this point once again tends to increase, it follows a "reloading" branch. This unloading/reloading branch can be defined by a single linear branch of stiffness $K_{u n / r e}$ that depends of the current magnitude of slip exactly before decreasing, which is named as $\delta_{m}$ in this study (see Figure 6a). If $0<\delta_{m} \leq \delta_{1}$, which means the slip is in the elastic bond phase, it is assumed that $K_{u n / r e}$ is calculated by $K_{u n / r e, e}=\tau\left(\delta_{m}\right) / \delta_{m}$ where $\tau\left(\delta_{m}\right)$ is the corresponding value of the bond shear stress at $\delta_{m}$ (see Figure 6a where $0<\delta_{m} \leq \delta_{1}$ ). For the cases where $\delta_{m}>\delta_{1}$, which means the slip is in the inelastic bond phase, 
$K_{u n / r e}=K_{u n / r e, i n}$ is assumed to be equal to $\tau_{1} / \delta_{1}$ similar to the idealized unloading/reloading of inelastic materials discussed in the plasticity theory [42] (see Figure 6a where $\delta_{1}<\delta_{m}$ ). Therefore, the value of $K_{\text {un/re }}$ is given by the following equation:

$$
K_{\text {un } / r e}\left(\delta_{m}\right)= \begin{cases}\frac{\tau\left(\delta_{m}\right)}{\delta_{m}} & \delta_{m}<\delta_{1} \\ \frac{\tau_{1}}{\delta_{1}} & \delta_{m} \geq \delta_{1}\end{cases}
$$

In fact, this unloading/reloading branch defines a permanent bond damage at the interface between the reinforcing bar and concrete. This damage is theoretically simulated by an irreversible slip, $\delta_{i r}$, that remains in the interface when the applied load is totally removed (see Figure 6a). For RC member under direct tension, this unloading/reloading phase may occur when a new crack formation stage starts (e.g. "secondary crack formation stage"). Figure 6b compares the slip distribution at primary and secondary crack formation stages. As shown, by forming a new crack (section $B$ in Figure 6b), slip at this new crack section tends to increase, while it tends to decrease at the already existing cracks. In order to consider the effect of increasing/decreasing of the slip in the theoretical formulation, an updated bond-slip constitutive law is used at the beginning of each new crackformation stage. This updated bond-slip law can be calculated using an average value of slip (named as $\delta_{m}$ ) at $x=L_{c r} / 2$ from the previous cracking stage, where $x$ has its origin from section C (see Figure 6b). Then the value of irreversible slip, $\delta_{i r}$, is calculated by:

$$
\begin{cases}\delta_{i r}=0 & \delta_{m} \leq \delta_{1} \\ \delta_{i r}=\delta_{m}-\frac{\tau\left(\delta_{m}\right)}{K_{u n / r e}} & \delta_{m}>\delta_{1}\end{cases}
$$

Figure 6a shows all possible updated bond-slip law according to the value of $\delta_{m}$.

\subsection{Effect of steel yielding strain on its bond behavior}

The tensile strain of steel bar at cracked section $\left(\varepsilon_{s}^{c r}\right)$ can exceed its yielding strain $\left(\varepsilon_{s y}\right)$, even if the mean value of tensile strain of the member is still less than the yielding strain [24]. This means that the steel bar is locally yielded at the cracked section. The yielding strain of steel bar affects its bond behavior [43]. Hence, this effect 
should be considered in the formulation. For this purpose, the $K_{b}$ factor proposed by Ruiz et al. [43] is adopted in this study to modify the bond-slip law of steel bar after yielding:

$$
\tau_{s}^{\bmod }\left(\delta_{s}\right)=K_{b} \cdot \tau_{s}\left(\delta_{s}\right)
$$

where

$$
K_{b}= \begin{cases}1 & \varepsilon_{s}^{c r} \leq \varepsilon_{s y} \\ e^{10\left(\varepsilon_{s y}-\varepsilon_{s}^{c r}\right)} & \varepsilon_{s}^{c r}>\varepsilon_{s y}\end{cases}
$$

After yielding of steel bar, the force transferred to the concrete by steel, $\left(V_{c}\right)_{s}$, which was previously calculated by Eq. (16), is now given by

$$
\left(V_{c}\right)_{s}=A_{s}\left(\sigma_{s y}-E_{s} \varepsilon_{s}^{m}\right) \quad \varepsilon_{s}^{c r}>\varepsilon_{s y}
$$

where $\sigma_{s y}$ is the yielding stress of steel bar, and $\varepsilon_{s}^{m}$ is the steel bar's strain at the midway section (see Figure 5), which is computed by FBL model (see Appendix A) by considering the modified bond shear stress provided by Eq. (25).

\subsection{Effect of pre-stress of reinforcing bars}

Applying pre-stress on internal embedded reinforcing bars enhances the structural performance of RC beams at serviceability limit states $[14,44]$. The pre-stressing force in RC beams creates an initial compressive strain in the concrete tensile zones and a negative camber to RC beam, which delays concrete to reach its tensile strength [44]. However, for uniaxial tensile member with a symmetric arrangement of reinforcements, pre-stress theoretically creates only an initial compressive strain that can be estimated from:

$$
\varepsilon_{c}^{p r e}=n_{s} \rho_{s} \varepsilon_{s}^{p r e}+n_{F} \rho_{F} \varepsilon_{F}^{p r e}
$$

where $\varepsilon_{c}^{\text {pre }}$ is the initial concrete compressive strain due to the pre-strain applied to steel $\left(\varepsilon_{s}^{\text {pre }}\right)$ and FRP bars $\left(\varepsilon_{F}^{\text {pre }}\right.$ ). The force due to the pre-stress of reinforcing bars is transferred to the member by the bond mechanism between reinforcing bars and surrounding FRC throughout the bond transferred length. The bond transferred length due to the pre-stress of reinforcing bars (i.e. $L_{t r}^{\text {pre }}$ ) can be calculated using IBL boundary conditions [27] as follow: 


$$
\left\{\begin{array}{l}
\frac{d \delta}{d x}=0 \text { at } x=0 \\
\frac{d \delta}{d x}=\varepsilon_{F}^{\text {pre }}\left(\text { or } \varepsilon_{s}^{p r e}\right) \text { at } x=L_{t r}^{p r e}
\end{array}\right.
$$

where $x$ origins from the extremity of the member where the pre-stress force is released. It should be noted that the RC system located beyond $L_{t r}^{p r e}$ behaves as a real composite similar to the "tie region", as previously explained.

\subsection{Tension-stiffening model}

The algorithm of the analysis procedure, which was described in the previous sections, is presented in Figure 7. At the beginning, the algorithm calculates the total applied force (i.e. $F$ ) by using IBL model [27] for both FRP and steel bars until formation of the first crack (Module 1). When first crack is formed, the algorithm calculates the total applied force by taking the strain compatibility condition of reinforcing bars, which was presented in Eq. (18), at right (using IBL model) and left sides (using FBL model) of this crack, as well as the contribution of

fibers (by using Eq. (14), where $w_{c r}=\left(\delta_{c r}\right)^{\text {Left }}+\left(\delta_{c r}\right)^{\text {Right }}$ ), (Module 2). If the value of $F$ reaches the cracking force of the member $\left(V_{c r}\right)$, the next crack is formed. The algorithm repeats the calculation process at the location of this new crack, which is now the last formed crack. This process continues until the bond progress of the reinforcing bars reaches the extremity of the member, by considering that

$$
\sum_{i=1}^{n_{c r}}\left(L_{c r}\right)_{i}>L_{e f f}
$$

where $n_{c r}$ is the number of cracks and $L_{e f f}$ is the total embedded length of reinforcing bars to the surrounding concrete, which is assumed to be equal to member's length in the further analysis. When Eq. (30) is satisfied, no "tie region" exists in the member, hence, the algorithm moves to Module 3, where the bond length $L_{b}$ is calculated as half of the average value of crack spacing from Module 2:

$$
2 L_{b}=\frac{\sum_{i=1}^{n_{c r}}\left(L_{c r}\right)_{i}}{n_{c r}}=\bar{L}_{c r}
$$

Consequently, the average value of crack width at the beginning of Module 3 is 


$$
\bar{w}_{c r}=\frac{\sum_{i=1}^{n_{c r}}\left(w_{c r}\right)_{i}}{n_{c r}}
$$

Then, for each increment of $\bar{w}_{c r}$, the total applied force is calculated by

$$
F=F_{r}+\left(V_{c}\right)_{f r}
$$

where $F_{r}$ is the total tensile force of the reinforcing bars, which is given by

$$
F_{r}= \begin{cases}E_{s} A_{s} \varepsilon_{s}^{c r}+E_{F} A_{F} \varepsilon_{F}^{c r} & \varepsilon_{s}^{c r} \leq \varepsilon_{s y} \\ A_{s} \sigma_{s y}+E_{F} A_{F} \varepsilon_{F}^{c r} & \varepsilon_{s}^{c r}>\varepsilon_{s y}\end{cases}
$$

$\varepsilon_{s}^{c r}$ and $\varepsilon_{F}^{c r}$ are computed by running the FBL model described in the Appendix A, and $\left(V_{c}\right)_{f r}$ is determined by Eq. (14).

Additionally, the total value of force transferred to the concrete matrix by the reinforcements, $\left(V_{c}\right)_{t}$, is calculated using Eq. (21). If $\left(V_{c}\right)_{t}$ reaches the cracking force of the member, i.e. $V_{c r}$, the midway section (A in Figure 5) cracks, in which the number of cracks becomes double, and the bond length becomes half of its value. The bondslip law of the reinforcing bars is updated based on the value of $\delta_{m}$, which was described in section 2.6.

Module 3 is repeated until FRP bar's strain meets its rupture strain. If steel bar yields before, the bond shear stress of steel bar is modified based on Eq. (25). In the model, a bi-linear elasto-plastic stress-strain relationship is considered for steel bar in tension. It is assumed that the ultimate tensile strain of FRP bar's $\left(\varepsilon_{F u}\right)$ is always reached before the steel tensile strain at hardening initiation $\left(\varepsilon_{s h}\right)$ is attained (Figure 8b). 


\section{DESCRIPTION OF FINITE ELEMENT (FE) MODEL}

The hybrid FRP/Steel FRC tensile member analyzed in the previous section is simulated by using Finite Element (FE) models available in FEMIX, a FEM-based computer program [45]. In this section some relevant information is given about the numerical model including FEs and constitutive laws adopted for concrete and reinforcements. Then, the predictive performance of the proposed analytical and FE models are appraised by simulating recent experimental tests dedicated to the tension-stiffening phenomenon.

\subsection{Finite elements}

Eight-node Plane Stress FEs are used to simulate concrete, with a Gauss-Legendre (G-L) integration scheme of $2 \times 2$, while the reinforcing bars are simulated by using 3-nodes Cable $2 \mathrm{D}$ elements with $2 \mathrm{G}$-L integration points. To simulate bond between the reinforcements and concrete, 6-nodes 2D Interface FEs are employed by using Gauss-Lobatto integration scheme of 3 points.

\subsection{Constitutive laws for the materials}

A multi-directional smeared crack model described in detail elsewhere [46], and available in FEMIX [45], is assigned to the Plane Stress FEs to simulate the elasto-cracked behavior of FRC. In this model, a linear and elastic constitutive law is adopted for concrete in compression and also in tension prior to crack initiation. When the tensile strength is attained in a certain integration point, the four-linear constitutive law shown in Figure 8a is followed in order to simulate the post-cracking response of FRC. In this figure, the parameter $G_{f}$ is the mode I fracture energy of FRC [40] and the parameter $l_{b}$ is the crack band width, which is assumed equal to the square root of the area assigned by each integration point in order to assure that the results are not dependent of the FE mesh refinement. $\varepsilon_{n}^{c r}$ and $\sigma_{n}^{c r}$ are the crack tensile strain and stress components, respectively, normal to the crack plane. The coefficients $\alpha_{i}$ and $\xi_{i}(i=1,2,3)$ define the transition points of the branches of the diagram.

The linear-elastic stress-strain diagram represented in Figure $8 \mathrm{~b}$ is adopted for FRP bars, where $\varepsilon_{F u}$ is the ultimate strain, while an elasto-plastic model [46] is employed to simulate the tensile behavior of steel bars, by using the following equation (Figure 8b): 


$$
\sigma_{s}\left(\varepsilon_{s}\right)= \begin{cases}E_{s} \varepsilon_{s} & \varepsilon_{s} \leq \varepsilon_{s y} \\ E_{s y}\left(\varepsilon_{s}-\varepsilon_{s h}\right)+\sigma_{s h} & \varepsilon_{s y}<\varepsilon_{s} \leq \varepsilon_{s h} \\ \sigma_{s u}+\left(\sigma_{s h}-\sigma_{s u}\right)\left(\frac{\varepsilon_{s u}-\varepsilon_{s}}{\varepsilon_{s u}-\varepsilon_{s h}}\right)^{p} & \varepsilon_{s h}<\varepsilon_{s} \leq \varepsilon_{s u} \\ 0 & \varepsilon_{s}>\varepsilon_{s u}\end{cases}
$$

where

$$
E_{s y}=\left(\sigma_{s h}-\sigma_{s y}\right) /\left(\varepsilon_{s h}-\varepsilon_{s y}\right)
$$

and $\varepsilon_{s y}, \varepsilon_{s h}, \varepsilon_{s u}, \sigma_{s y}, \sigma_{s h}$ and $\sigma_{s u}$ are defined in Figure 8b. The parameter $p$ normally ranged between 1 and 4.

\subsection{Interface behavior}

The sliding component of the constitutive model for the Interface FEs is defined by the bond-slip relationship represented in Figure 3b, which is characterized by the following three branches [26, 46]:

$$
\tau(\delta)=\left\{\begin{array}{l}
\tau=\tau_{1} \cdot\left(\delta / \delta_{1}\right) \quad 0 \leq \delta \leq \delta_{1} \\
\tau=\tau_{m} \cdot\left(\delta / \delta_{2}\right)^{\beta_{1}} \quad \delta_{1}<\delta \leq \delta_{2} \\
\tau=\tau_{m} \cdot\left(\delta / \delta_{2}\right)^{-\beta_{2}} \quad \delta>\delta_{2}
\end{array}\right.
$$

where $\delta_{1}=\delta_{2}\left(\tau_{1} / \tau_{m}\right)^{1 / \beta_{1}}$.

\subsection{Geometry, mesh and boundary conditions}

Figure 9 shows the typical scheme of tension-stiffening specimens used in experiments, as well as the mesh and geometry of FE model proposed in the present study. As shown, the FE model has a line of symmetry through its axis at center of the section. The interface elements are located at this symmetric line, where the axial stiffness of the reinforcing bar sets as half value. The interface elements are assigned only to the bonded area as shown in this Figure. 


\section{MODEL VALIDATION}

Two sets of data of RC in direct tension tests have been selected from the literature. The first is GFRP-RC carried out by Baena et al. in 2011 [47], and the second belongs to the work recently carried out by Moreno et al. in 2014 on Hybrid Fiber-Reinforced Concrete (named as "HyFRC") containing conventional steel bar [17]. For the second one [17], the bond-slip law suggested by CEB-FIB Model Code 2010 [28] for steel bars is adopted. However, for the first one, the local bond-slip law of the used GFRP bar is calibrated by employing the bond model proposed by Mazaheripour et al. [27] by fitting the theoretical pullout force versus loaded end slip to the experimental results of the direct pullout tests presented by the same authors in 2009 [48]. It is worth noticing that the bond length in their tests was five times of the GFRP bar's diameter [48]. Table 1 reports the values that define the bond-slip law used in the proposed numerical models, and Table 2 includes the relevant properties of the used concrete and FRC, and reinforcements, which were reported in $[17,47]$.

Additionally, the post-cracking behavior of "HyFRC" is simulated by the diagram represented in Figure 8a, whose data for its definition $\left(\xi_{i}, \alpha_{i}\right.$ and $\left.G_{f}\right)$ was obtained by fitting the post-cracking response recorded in the uniaxial tensile tests carried by Moreno et al. [17]. In case of analytical model, the contribution of fibers are obtained by subtracting the concrete softening from the given post-cracking response of "HyFRC" [49]. The concrete softening is obtained by using the bi-linear diagram recommended by CEB-FIB Model Code 2010 [28]. Figure 10a shows the contribution of fibers, and the total post-cracking stress-strain diagram of "HyFRC" that is used in the analytical model and FE model, respectively.

In Figure 10b, 11a, b and $\mathrm{c}$ the experimental results are compared to those obtained by the proposed analytical and FE models. By giving the relevant input data that defines the material properties of concrete, reinforcing bar, and the bond-slip law's parameters, the models predict well the experimental results.

Moreover, Figure 10c and Figure 11d compare the crack pattern obtained experimentally and numerically. The FE model predicts fairly in an acceptable way the experimental crack pattern registered in the GFRP-RC specimens. However, in the simulation of the tensile response of HyFRC the crack pattern obtained by FE model showed some differences in terms of number of cracks and crack spacing since the model is not simulating the influence of fiber distribution and orientation on the post-cracking behavior of HyFRC. To take these aspects into consideration, more sophisticated models should be used, like the one detailed in [50]. 


\section{PARAMETRIC STUDY}

By using the proposed analytical model, two groups of parametric studies, A and B, are carried out to evaluate the influence of the main model parameters on the variations of tensile stress of reinforcing bars due to their bond interaction to surrounding concrete, which is defined as tension-stiffening effect $f_{r, T S}$ hereafter. For this purpose, a FRC tensile member containing FRP and steel bars in a symmetric arrangement in the concrete section is considered to be subjected to direct tension load. The effective embedded length of the reinforcing bars ( $\left.L_{e f f}\right)$ is assumed equal to $1000 \mathrm{~mm}$. In this work, the properties of the adopted FRP bars correspond to the type of Schöck ribbed GFRP bars previously tested by the authors [51]. The typical properties of mild steel that is being used in construction industry are also taken for the steel bars in this study. Finally, three types of FRCs (named FRC1, FRC2 and FRC3), with different values of mode I fracture energy $\left(G_{f}\right)$, are considered to be representative of a concrete mix with different volume fraction of fibers. Figure 12 compares the post-cracking behavior of FRC1, 2 and 3 in terms of the parameter $\alpha$ versus $\xi$ as they were defined earlier in Figure $4 \mathrm{~b}$, and the respective values are written in Table 3 The contribution of fibers after cracking is simply defined by using the same four-linear post-cracking response of FRC shown in Figure 12, but having the first point starts at $(0,0)$, that is null values for the both $\alpha$ and $\xi$ (see dotted line in Figure 12). This represents in a simple manner how the pullout force by fibers starts increasing from null value while the crack is opening (or increase in crack strain).

\subsection{Studies of Group A}

Group A includes 10 different studies that focus on the influence of the steel versus FRP reinforcement ratio (i.e. $\left.\rho_{s} / \rho_{F}\right)$ and concrete fracture energy mode $\mathrm{I}, G_{f}:$

- Studies 1 to 5: the steel reinforcement ratio, $\rho_{s}$, is varied by adopting different steel bars in terms of diameter $(\varnothing 12,14,16,20$ and $25 \mathrm{~mm})$, while the properties of concrete and GFRP reinforcement ratio (4Ø8 GFRP) are kept constant. Plain concrete (without fibers) is used in these studies;

- Studies 6 to 7: The reinforcement arrangement of Study 3 (i.e. $4 \times \emptyset 8$ GFRP $+1 \times \emptyset 16$ steel) with a total reinforcement ratio of $\rho=\rho_{s}+\rho_{F}=1.30 \%$ is adopted in these studies, but for Study $6, \rho_{s}$ is assumed to be null, which means no steel bars are used [i.e. $(4 \times \varnothing 8+1 \times \emptyset 16)$ GFRP], while in Study 7 no GFRP bars are applied [i.e. $(4 \times \varnothing 8+1 \times \emptyset 16)$ Steel]. 
- Studies 8 to 10: the hybrid reinforcement of Study 3 is used for studies 8 to 10 , but the $G_{f}$ varies by taking FRC type 1, 2 and 3;

Although different bars' diameter are used in Studies 1 to 10, the bond-slip law's parameters are kept constant in order to neglect the effect of bond-slip law's parameters in these studies. Table 3 reports the properties of the used materials in Studies 1 to 10. The values that define the bond-slip relationship for these studies are indicated in the first row of Table 4.

\subsection{Group B}

Group B includes 6 studies, $11^{\text {th }}$ to $16^{\text {th }}$, that aim to assess the influence of the bond-slip law's parameters of GFRP bars on the variation of $f_{r, T S}$. The type of concrete, the reinforcement ratio and arrangement are those adopted in Study 3. Note that the bond-slip law's parameters of steel bar are constant in the analysis of Group B.

- Studies 11 to 13 the stiffness of the first and second linear branches of $\tau-\delta$ diagram (shown in Figure 3a) are defined as $K_{1}$ and $K_{2}$, respectively. Then, they are calculated by

$$
\left\{\begin{array}{l}
K_{1}=\frac{\tau_{1}}{\delta_{1}} \\
K_{2}=\frac{\left(\tau_{m}-\tau_{1}\right)}{\left(\delta_{2}-\delta_{1}\right)}
\end{array}\right.
$$

In Studies 11 to 13, the value of $K_{1}$ is varied by changing the value of $\delta_{1}$ (Figure 13a). However, the value of $\delta_{2}$ is adjusted in order to keep the value of $K_{2}$ constant and equals to the value defined in Study 3. In this case, $\delta_{2}$ is calculated by

$$
\delta_{2}=\frac{\left(\tau_{m}-\tau_{1}\right)}{K_{2}}+\delta_{1}
$$

The values of $\tau_{1}$ and $\tau_{m}$ are those adopted in Study 3, since the concrete compressive strength $\left(f_{c m}\right)$ is considered equal in all studies, and considering that the bond strength of a bar-concrete interface is commonly presented as function of $f_{\mathrm{cm}}{ }^{1 / 2}$;

- Studies 14 to 16: the value of $K_{2}$ is varied by changing only the value of $\delta_{2}$ (Figure 13b). The other parameters are the same adopted in Study 3; 
Table 4 includes the bond-slip law's parameters adopted in all the studies. As shown in Figure 13, the alteration of the stiffness of the pre-peak branches can be simulated by changing the power value of $\beta_{1}$ with a bond-slip diagram similar to the one adopted in the FE model (Figure 3b), which has already been used by many authors $[23,24,46,52]$.

\subsection{Results and discussion}

The tension-stiffening effect, $f_{r, T S}$, is defined as the portion of tensile stress of reinforcing bars at crack section that is carried by the surrounding concrete due to the bond behavior of reinforcing bars. Based on this definition, $f_{r, T S}$ is determined by:

$$
f_{r, T S}=\frac{1}{A_{c}}\left(F_{r}-F_{b a r e}\right)
$$

where $F_{\text {bare }}$ is the tensile force of bare bars (un-bonded bars):

$$
F_{\text {bare }}=\left(E_{s} A_{s}+E_{F} A_{F}\right) \bar{\varepsilon}
$$

being $\bar{\varepsilon}$ the mean strain of member, if the elastic defomration of FRC between cracks is neglected, the mean value is simply obtained by:

$$
\bar{\varepsilon}=\frac{\bar{w}_{c r}}{\bar{L}_{c r}}+\bar{\varepsilon}_{c r}
$$

where $\bar{L}_{c r}$ and $\bar{w}_{c r}$ are obtained according to equations (31) and (32), respectively, and $\bar{\varepsilon}_{c r}$ is the elastic mean strain of member at cracking point. By substituting Eq. (34) to Eq. (40), $f_{r, T S}$ becomes:

$$
f_{r, T S}= \begin{cases}\rho_{s} E_{s}\left(\varepsilon_{s}^{c r}-\bar{\varepsilon}\right)+\rho_{F} E_{F}\left(\varepsilon_{F}^{c r}-\bar{\varepsilon}\right) & \varepsilon_{s}^{c r} \leq \varepsilon_{s y} \\ \rho_{s}\left(\sigma_{s y}-E_{s} \bar{\varepsilon}\right)+\rho_{F} E_{F}\left(\varepsilon_{F}^{c r}-\bar{\varepsilon}\right) & \varepsilon_{s}^{c r}>\varepsilon_{s y}\end{cases}
$$

Hereafter the normalized tensile stress, $f_{r, T S} / f_{c t}$, is used being $f_{c t}$ the concrete tensile strength.

\subsubsection{Normalized $f_{r, T S} / f_{c t}$ versus member's mean strain}

Figure 14a and b present the results of the parametric study of group A (studies 1 to 5, and 8 to 10), and Figure $14 \mathrm{c}$ and $\mathrm{d}$ show the results obtained from the parametric study of group B (studies 11 to 16), both in terms of 
$f_{r, T S} / f_{c t}$ versus mean strain of the member $(\bar{\varepsilon})$. In accordance with the tension-stiffening responses obtained from the results of the parametric study, a multi-linear diagram presented in Figure 15 can be proposed for tensionstiffening model of concrete (or FRC) member reinforced by hybrid FRP/steel bars. This diagram can be defined by three coefficients of, $\zeta_{j}, \psi_{i}$, and $\eta_{i}$ (i=1 to $3, j=1$ to 4 and $j=1$ to 5$)$ where:

- Values of $\zeta_{j} \varepsilon_{c r}$ define the level of concrete tensile strain $\left(\varepsilon_{c t}\right)$ due to the tension-stiffening effects, in which $\zeta_{1}$ corresponds to the concrete crack tensile strain at the beginning of the primary crack formation stage, $\zeta_{2}$ corresponds to the concrete tensile strain at the initiation of steel yielding at crack section while $\zeta_{3}$ defines the concrete tensile strain equals to steel yielding strain (i.e. $\varepsilon_{c t}=\varepsilon_{s y} \approx 30 \varepsilon_{c r}$ ), $\zeta_{4}$ defines the concrete crack tensile strain corresponding to reinforcing bar's slip $\left(\delta_{c r}\right)$ at the end of the elastic bond phase $\left(\delta_{1}\right)$, and finally, $\zeta_{5}$ defines the concrete tensile strain at rupture of FRP bar.

- Values of $\psi_{i} f_{c t}$ define the level of concrete tensile stress ( $\left.\sigma_{c t}\right)$ due to the tension stiffening, in which $\psi_{1}$ to $\psi_{4}$ define the crack tensile stress corresponding to $\zeta_{1}$ to $\zeta_{4}$, respectively.

- Values of $\eta_{i} E_{c}$ define the stiffness of the ascending linear branches of the model (pseudo-hardening stages), in which $\eta_{i}$ corresponds to the axial stiffness of the reinforcing bars, as well as their bond stiffness by $\tau-\delta$ diagram.

By fitting the proposed diagram to the tension-stiffening responses shown in Figure 14, the variation of these coefficients versus the parametric variables of $\rho_{s} / \rho_{F}, G_{f}, K_{1}$ and $K_{2}$ are determined, and plotted in Figure 16.

\section{Effect of increasing the steel reinforcement ratio $\left(\rho_{s} / \rho_{F}\right)$ :}

When the steel reinforcement ratio increases, the average crack spacing $\left(\bar{L}_{c r}\right)$, as well as the bond length $\left(L_{b}\right)$ decreases. Hence, by increasing the slip of reinforcing bars at crack section, the difference between $\varepsilon_{r}^{c r}$ and $\varepsilon_{r}^{m}$ in Eq. (16) for both FRP and steel bars decreases, and based on Eq. (42), the mean value of $\bar{\varepsilon}$ approaches to the value of $\varepsilon_{r}^{c r}$. Therefore, the tension-stiffening effect calculated by Eq. (44) decreases. This was evidenced from 
the obtained results plotted in Figure 14a, as well as the decrease in the value of coefficients $\psi_{i}$ versus $\rho_{s} / \rho_{F}$ in Figure 16. Before yielding of steel bar, by increasing $\rho_{s}, \eta_{1}$ increase due the increase in the axial stiffness of the steel bars. However, after yielding of the steel, the value of $\eta_{2}$ and $\eta_{3}$ decrease due to the significant drop in the axial stiffness of steel bar at cracked section, as well as the increase in its bond stiffness (by Eq. (25)).

Additionally, when $\left(\varepsilon_{r}^{c r}-\bar{\varepsilon}\right)$ decreases, coefficients $\zeta_{2}$ and $\zeta_{5}$ increase, in which $\zeta_{2}$ gets closer value to $\varepsilon_{s y} \approx 30 \varepsilon_{c r}$, and $\zeta_{5}$ to the level of strain at rupture of $\operatorname{FRP}\left(\varepsilon_{f u} \approx 167 \varepsilon_{c r}\right)$.

\section{Effect of increasing the fracture energy of FRC}

When of the mode I fracture energy $\left(G_{f}\right)$ increases, the number of cracked sections in the member increases significantly, leading to a smaller average crack spacing. Therefore, similar to what already explained, the $\left(\varepsilon_{r}^{c r}-\bar{\varepsilon}\right)$ parcel of Eq. (43) decreases with the increase of the slip at cracked section. Since in these studies the reinforcement ratios $\left(\rho_{F}\right.$ and $\rho_{s}$ ) are constant, the decrease in the tension-stiffening effect calculated by Eq. (43) is more noticeable (comparing the obtained results in Figure 14a and Figure 14b). The same tendency that was previously obtained for $\psi_{i}, \eta_{i}$ and $\zeta_{j}$ when $\rho_{s}$ is increased, is also obtained with the increase of $G_{f}$. However, in the present studies the $\eta_{1}$ is almost constant since the axial stiffness of the steel bar does not change (see Figure 16, variation of the model coefficient versus $G_{f}$ ).

\section{Effect of increasing the stiffness of elastic bond phase of FRP bar $\left(K_{1}\right)$}

By increasing the stiffness of the elastic branch of bond law assumed for FRP bar (i.e. $K_{1}$ ), the tension-stiffening effect of reinforcing bars increases. This can be evidenced by the obtained results shown in Figure 14c, as well as the increase in coefficient $\psi_{i}$ versus the variation of $K_{1}$ in Figure 16. When $K_{1}$ increases, the parcel $\left(\varepsilon_{r}^{c r}-\varepsilon_{r}^{m}\right)$

of Eq. (16) increases, and considering that $\varepsilon_{r}^{m} \cong \bar{\varepsilon}$ (Eq. (43)), the $f_{r, T S}$ determined from Eq. (44) also increases.

On the other hand, if the parcel $\left(\varepsilon_{F}^{c r}-\bar{\varepsilon}\right)$ increases, FRP bar attains its ultimate strain $\left(\varepsilon_{F u}\right)$ at lower level of the concrete crack tensile strain, which can be seen by the variation of $\zeta_{4}$ versus $K_{1}$ in Figure 16. 
Additionally, $\eta_{1}$ and $\eta_{2}$ increase with $K_{1}$, while $\eta_{3}$ is not significantly affected for the variation of this parameters because for $\varepsilon_{c t}>\zeta_{3} \varepsilon_{c r}$ the slip of FRP bars at crack section is not in its elastic bond phase.

\section{Effect of increasing the stiffness of hardening bond phase of FRP bars $\left(K_{2}\right)$}

For the material properties and the bond-slip relationship adopted in this study, Figure $14 \mathrm{~d}$ shows that $K_{2}$ has a negligible effect on the variation of tension stiffening $f_{r, T S}$. Only the stiffness of the third linear branch $\left(\eta_{3}\right)$ is influenced by the variation of $K_{2}$. This is due to the fact that for the concrete cracking strain greater than $\zeta_{3} \varepsilon_{c r}$, the slip of FRP bar at crack section is beyond the elastic bond phase of the bond diagram, and consequently it is influenced by the value of $K_{2}$.

\subsubsection{Total force versus the average crack width and the mean strain}

In Figure 17a the total force versus the average crack width (i.e. $\bar{w}_{c r}$ ) obtained in the studies 6 and 7 , corresponding to the GFRP-RC and Steel-RC tensile member, are compared to the hybrid GFRP-Steel RC tensile member of Study 3. The enhancement in terms of crack width by adding steel reinforcement to the GFRP-RC member is observable. Note that the same total reinforcement ratio of $1.3 \%$ was adopted for the three studies. However, after yielding of steel, the crack width increases considerably due to the significant loss in the steel axial stiffness, as well as its bond to concrete.

In addition to the analytical results obtained from the parametric studies of 3, 6 and 7, FE analysis were carried out by using FEMIX, and the results obtained from the simulation are compared with the analytical ones in terms of the total force versus average crack width and mean strain, which are plotted in Figure 17a and 17b, respectively. The average crack width in the FE model was obtained by computing the average value of inelastic deformation of the integration points at the location of the main cracks for different load combinations. The inelastic deformation of the integration points was calculated by multiplying the crack tensile strain in loading direction by the crack band width $\left(l_{b}\right)$. As a results, a good agreement between both models was achieved.

\subsubsection{Post-cracking response of FRC including tension-stiffening effect}


In case of modeling of RC members, if the bond-slip behavior of reinforcing bars and concrete is not simulated, the tension-stiffening effect due to the reinforcements is normally performed through the concrete tensile stressstrain relationship in order to get more accurate results. This is the same concept when S- FRC or FRP reinforced FRC members are simulated. The tension-stiffening of FRP and steel bars due to their bond behavior with FRC should be included in the post-cracking behavior of FRC, which is normally obtained by uniaxial tensile tests.

In this context, if the tension-stiffening response obtained from the parametric studies of 8 to 10 , shown in Figure 14b, is added to the respective post-cracking response of FRCs, shown in Figure 12, the total post-cracking response of hybrid FRP/steel reinforced FRC including the tension-stiffening effect of the reinforcing bars is attained. Figure 18 compares the post-cracking response of FRC1, 2 and 3 with and without the tension stiffening effect. This figure is plotted in terms of dimensionless coefficient of $\alpha$ versus $\xi$, where the black dots show the failure of FRP bars corresponding to the attainment of the ultimate tensile strain adopted for FRP bars (see Table 3). The post-cracking response of hybrid reinforced FRC is appropriate to be used in the finite elemental or sectional analysis where the interfacial bond behavior between reinforcing bar and FRC is ignored. 


\section{CONCLUSIONS}

In the present work, the tension-stiffening effect due to the bond interaction between a hybrid reinforcement system composed by fiber reinforced polymer (FRP) and steel bars and surrounding fiber reinforced concrete (FRC) was theoretically investigated through an explicit analytical formulation. The analytical model is based on the bondslip behavior of the reinforcing bars and the surrounding FRC, as well as the post-cracking response of FRC in tension. The tension-stiffening effect was also investigated by employing $2 \mathrm{D}$ interface finite elements using a constitutive model that simulates the bond behavior of reinforcing bars and concrete. This interface was used to connect 2D Cable elements to 2D Plane Stress finite elements, which simulate concrete employing a multidirectional smeared crack approach. With a basis of the results from the proposed model, the following conclusion can be drawn:

1) The two analytical and numerical models showed a good agreement with some recent experimental tests available in the literature in case of GFRP reinforced tensile member and S-FRC tensile member, leading to show their capability to address to the tension-stiffening effect of such reinforced members.

2) The post-yielding of steel bar as well as the loss in its bond to concrete was modeled through an empirical coefficient. This gives possibility of modeling the decrease in tension stiffening effect of steel-RC element after yielding of steel bar.

3) Based on the results of parametric study, increase in mode I fracture energy of FRC will reduce the tensionstiffening effect by reinforcing bars in reinforced FRC members. This is attributed to the fact that the higher fracture energy results in higher number of cracks and lower crack spacing, and consequently, lower bond length. If the bond length decreases, tension stiffening significantly decreases. On the other hand, the higher fracture energy decrease the average crack width, which is beneficial for serviceability limit state requirements.

4) An improve in terms of crack width and load carrying capacity can be observed for the hybrid FRP-steel reinforced FRC member if the steel reinforcement ratio increases. However, after yielding of the steel bar, this hybrid system showed the higher average crack width when it compares with the FRP reinforced FRC member without steel bar (in case of the same total reinforcement ratio for both reinforced member). 
5) The tension-stiffening effect of hybrid steel/GFRP reinforced FRC element was introduced as a modified crack stress-strain diagram of FRC in which a fracture energy higher than its original value was adopted before rupturing strain of GFRP. This modification is based on the properties of the reinforcing bars and their bond-slip characterizations. The modified crack tensile stress-strain diagram is functional to be used in the sectional or finite elemental analysis of hybrid FRP/steel reinforced FRC elements where no attempt is made to simulate the effect of bond-slip behavior of the reinforcing bars.

It should be noticed that the influence of concrete cover, reinforcing bar's diameter, and concrete splitting are not considered in the proposed model. However, their effectiveness can be simply added to the model if the relevant bond-slip law including those effect is adopted in the model. In addition, the discrete crack analysis proposed in this study may not be functional for cement-based composite materials that exhibits strain-hardening behavior after cracking. 


\section{Acknowledgment}

This work is supported by FEDER funds through the Operational Programme of North, QREN project n. 30367 UrbanCrete. The first author aknowledges the PhD Grant SFRH/BD/77409/2011 provided by the FCT Portuguese Foundation for Science and Technology. 


\section{REFERENCES}

[1] Choi, D.-U., Chun, S.-C., and Ha, S.-S., Bond strength of glass fibre-reinforced polymer bars in unconfined concrete. Engineering Structures, 2012. 34: p. 303-313.

[2] Harajli, M. and Abouniaj, M., Bond performance of GFRP bars in tension: Experimental evaluation and assessment of ACI 440 guidelines. Journal of Composites for Construction, 2010. 14(6): p. 659-668.

[3] Rasheed, H. A., Nayal, R., and Melhem, H., Response prediction of concrete beams reinforced with FRP bars. Composite Structures, 2004. 65(2): p. 193-204.

[4] Toutanji, H. A. and Saafi, M., Flexural behavior of concrete beams reinforced with glass fiber-reinforced polymer (GFRP) bars. ACI structural journal, 2000. 97(5).

[5] Benmokrane, B., Chaallal, O., and Masmoudi, R., Flexural response of concrete beams reinforced with FRP reinforcing bars. ACI Structural Journal, 1996. 93(1).

[6] ACI Committee 440, Guide for the design and construction of structural concrete reinforced with FRP bars (ACI 440.1R-06). 2006: American Concrete Institute, Farmington Hills, MI, USA.

[7] Japan Society of Civil Engineers (JSCE), Recommandation for design and construction of concrete structure using continous fiber reinforcing materials. 1997: N23, Concrete engineering series, Japan.

[8] CEB-FIB, FRP reinforcement in RC structures. 2007: fib Task Group 9.3, Bulletin No. 40.

[9] Canadian Standard Association (CSA), Design and construction of building component with fiber-reinforced polymers. 2002: CSA Standard S806-02, Toronto, Cananda.

[10] Taheri, M., Barros, J. A. O., and Salehian, H., A design model for strain-softening and strain-hardening fiber reinforced elements reinforced longitudinally with steel and FRP bars. Composites Part B: engineering, 2011. 42(6): p. 1630-1640.

[11] Aiello, M. A. and Ombres, L., Structural Performances of Concrete Beams with Hybrid Fiber-Reinforced Polymer-Steel Reinforcements. Journal of Composites for Construction, 2002. 6(2): p. 133-140.

[12] Qu, W., Zhang, X., and Huang, H., Flexural Behavior of Concrete Beams Reinforced with Hybrid (GFRP and Steel) Bars. Journal of Composites for Construction, 2009. 13(5): p. 350-359. 
[13] Soltanzadeh, F., Barros, J. A. O., and Santos, R. F. C., High performance fiber reinforced concrete for the shear reinforcement: Experimental and numerical research. Construction and Building Materials, 2015. 77: p. 94-109.

[14] Soltanzadeh, F., Mazaheripour, H., Barros, J. A., Taheri, M., and Sena-Cruz, J. Experimental study on shear behavior of HPFRC beams reinforced by hybrid pre-stressed GFRP and steel bars. in The 7th International Conference on FRP Composites in Civil Engineering (CICE 2014). 2014. Vancouver, Canada.

[15] Abrishami, H. H. and Mitchell, D., Influence of Steel Fibers on Tension Stiffening. ACI Structural Journal, 1997. 94(6): p. 769-776.

[16] Bischoff, P. H., Tension Stiffening and Cracking of Steel Fiber-Reinforced Concrete. Journal of Materials in Civil Engineering, ASCE, 2003. 15(2): p. 174-182.

[17] Moreno, D. M., Trono, W., Jen, G., Ostertag, C., and Billington, S. L., Tension stiffening in reinforced high performance fiber reinforced cement-based composites. Cement \& Concrete Composites, 2014. 50: p. 3646.

[18] Sooriyaarachchi, H., Pilakoutas, K., and Byars, E. Tension Stiffening Behavior of GFRP-Reinforced Concrete. in 7th International Symposium on Fiber Reinforced Polymer Reinforcement for Reinforced Concrete Structures (FRPRCS-7). 2005. New Orleans, Louisiana, USA.

[19] Vilanova, I., Torres, L., Baena, M., Kaklauskas, G., and Gribniak, V., Experimental study of tension stiffening in GFRP RC tensile members under sustained load. Engineering Structures, 2014. 79(15): p. 390-400.

[20] Bischoff, P. H. and Paixao, R., Tension stiffening and cracking of concrete reinforced with glass fiber reinforced polymer (GFRP) bars. Canadian Journal of Civil Engineering, 2004. 31(4): p. 579-588.

[21] Nayal, R. and Rasheed, H. A., Tension Stiffening Model for Concrete Beams Reinforced with Steel and FRP Bars. Journal of Materials in Civil Engineering, ASCE, 2006. 18(6): p. 831-841.

[22] Aiello, M. A. and Ombres, L., Cracking analysis of FRP-reinforced concrete flexural members. Mechanics of Composite Materials, 2000. 36(5): p. 389-394. 
[23] Baena, M., Torres, L., Turon, A., and Miàs, C., Analysis of cracking behaviour and tension stiffening in FRP reinforced concrete tensile elements. Composites Part B: engineering, 2013. 45(1): p. 1360-1367.

[24] Lee, S., Cho, J., and Vecchio, F., Tension-stiffening model for steel fiber-reinforced concrete containing conventional reinforcement. ACI Structural Journal, 2013. 110(4): p. 639-648.

[25] Gribniak, V., Mang, H. A., Kupliauskas, R., and Kaklauskas, G., Stochastic Tension-Stiffening Approach for the Solution of Serviceability Problems in Reinforced Concrete: Constitutive Modeling. ComputerAided Civil and Infrastructure Engineering, 2015 (DOI: 10.1111/mice.12133).

[26] Pepe, M., Mazaheripour, H., Barros, J., Sena-Cruz, J., and Martinelli, E., Numerical calibration of bond law for GFRP bars embedded in steel fibre-reinforced self-compacting concrete. Composites Part B: engineering, 2013. 50: p. 403-412.

[27] Mazaheripour, H., Barros, J. A. O., Sena-Cruz, J., and Soltanzadeh, F., Analytical Bond Model for GFRP Bars to Steel Fiber Reinforced Self-Compacting Concrete. Journal of Composites for Construction, 2013. 17(6): p. 04013009.

[28] CEB-FIB, Model Code 2010 - Final draft. 2010: Thomas Thelford, Lausanne, Switzerland.

[29] Hordijk, D. A., Local approach to fatigue of concrete. 1991: Delft University of Technology.

[30] Bianco, V., Barros, J. A., and Monti, G., Bond model of NSM-FRP strips in the context of the shear strengthening of RC beams. Journal of Structural Engineering, 2009. 135(6): p. 619-631.

[31] Malvar, L. J., Tensile and bond properties of GFRP reinforcing bars. ACI Materials Journal, 1995. 92(3).

[32] Cosenza, E., Manfredi, G., and Realfonzo, R., Behavior and modeling of bond of FRP rebars to concrete. Journal of composites for construction, 1997. 1(2): p. 40-51.

[33] Cunha, V. M. C. F., Steel Fibre Reinforced Self-Compacting Concrete (from Micro-Mechanics to Composite Behaviour). 2010, Guimaraes, Portugal: University of Minho.

[34] Wang, Y., Mechanics of fiber reinforced cementitious composites. 1989, PhD Thesis, Massachusetts Institute of Technology (MIT), USA. 
[35] Kreyszig, E., Advanced Engineering Mathematics. 1993, Berlin: John Wiley \& Sons.

[36] Cunha, V. M. C. F., Barros, J. A. O., and Sena-Cruz, J. M., Pullout behaviour of steel fibres in selfcompacting concrete. Journal of Materials in Civil Engineering (ASCE), 2010. 22(1): p. 1-9.

[37] Lee, S.-C., Cho, J.-Y., and Vecchio, F. J., Diverse Embedment Model for Steel Fiber-Reinforced Concrete in Tension: Model Development. ACI Materials Journal, 2011. 108(5): p. 516-525.

[38] Abrishambaf, A., Barros, J. A. O., and Cunha, V. M. C. F., Relation between fibre distribution and postcracking behaviour in steel fibre reinforced self-compacting concrete panels. Cement and Concrete Research, 2013. 51: p. 57-66.

[39] Pereira, E. B., Fischer, G., and Barros, J. A., Direct assessment of tensile stress-crack opening behavior of Strain Hardening Cementitious Composites (SHCC). Cement and Concrete Research, 2012. 42(6): p. 834846.

[40] Barros, J. and Sena Cruz, J., Fracture energy of steel fiber-reinforced concrete. Mechanics of Composite Materials and Structures, 2001. 8(1): p. 29-45.

[41] Visintin, P., A generic segmental analysis of all types of RC members. University of Adelaide, Adelaide, Australia, 2012.

[42] Jones, R. M., Deformation theory of plasticity. 2009: Bull Ridge Corporation.

[43] Ruiz, M. F., Muttoni, A., and Gambarova, P., Analytical modeling of the pre-and postyield behavior of bond in reinforced concrete. Journal of Structural Engineering, 2007. 133(10): p. 1364-1372.

[44] Rezazadeh, M., Costa, I., and Barros, J., Influence of prestress level on NSM CFRP laminates for the flexural strengthening of RC beams. Composite Structures, 2014. 116: p. 489-500.

[45] Sena-Cruz, J., Barros, J. A., Azevedo, Á. F., and Gouveia, A. V. Numerical simulation of the nonlinear behavior of RC beams strengthened with NSM CFRP strips. in CMNE 2007 - Congress on Numerical Methods in Engineering and XXVIII CILAMCE - Iberian Latin American Congress on Computational Methods in Engineering,. 2007. FEUP, Porto, Portugal. 
[46] Sena Cruz, J., Strengthening of concrete structures with near-surface mounted CFRP laminate strips. 2004, PhD Thesis, Universidade do Minho: Guimaraes, Portugal.

[47] Baena, M., Turon, A., Torres, L., and Miàs, C., Experimental study and code predictions of fibre reinforced polymer reinforced concrete (FRP RC) tensile members. Composite Structures, 2011. 93(10): p. 25112520.

[48] Baena, M., Torres, L., Turon, A., and Barris, C., Experimental study of bond behaviour between concrete and FRP bars using a pull-out test. Composites Part B: Engineering, 2009. 40(8): p. 784-797.

[49] Moreno, D. M., Trono, W., Jen, G., Ostertag, C., and Billington, S. L., Tension-Stiffening in Reinforced High Performance Fiber-Reinforced Cement-Based Composites under Direct Tension, in High performance fiber reinforced cement composites 6, R.H. Parra-montesinos GJ, Naaman AE, Editor. 2012, Springer. p. 263-70.

[50] Cunha, V. M., Barros, J. A., and Sena-Cruz, J., An integrated approach for modelling the tensile behaviour of steel fibre reinforced self-compacting concrete. Cement and Concrete Research, 2011. 41(1): p. 64-76.

[51] Mazaheripour, H., Barros, J. A. O., Sena Cruz, J. M., Pepe, M., and Martinelli, E., Experimental study on bond performance of GFRP bars in self-compacting steel fiber reinforced concrete. Composite Structures, 2013. 95: p. 202-212.

[52] Focacci, F., Nanni, A., and Bakis, C. E., Local bond-slip relationship for FRP reinforcement in concrete. Journal of composites for construction, 2000. 4(1): p. 24-31. 


\section{Appendix A}


Some constant parameters during the analysis: $C_{e}=\frac{\tau_{1} J_{r}}{\lambda_{1}^{2}} ; \lambda_{1}=\sqrt{\frac{\left(\tau_{1}-\tau_{0}\right)}{\delta_{1}} J_{r}} ; C_{h}=\frac{\tau_{m} J_{r}}{\lambda_{2}{ }^{2}} ; \lambda_{2}=\sqrt{\frac{\left(\tau_{m}-\tau_{1}\right)}{\left(\delta_{2}-\delta_{1}\right)} J_{r}} ; C_{p}=\frac{\tau_{m} J_{r}}{2} ; C_{s o}=\frac{\tau_{m} J_{r}}{\gamma^{2}} ; \gamma=\sqrt{\frac{\left(\tau_{m}-\tau_{R}\right)}{\left(\delta_{4}-\delta_{3}\right)}} J_{r} ; C_{f}=\frac{\tau_{R} J_{r}}{2}$

\begin{tabular}{|c|c|c|c|c|c|}
\hline 密 & $\begin{array}{r}\text { Slip functions } \delta(x) \\
\Rightarrow\end{array}$ & $\begin{array}{l}\text { Boundary } \\
\text { conditions }\end{array}$ & Slip solutions & Compatibility conditions & $\begin{array}{l}\text { Equations derived by considering compatibility } \\
\text { conditions }\end{array}$ \\
\hline 1 & $\begin{array}{r}\mathrm{C}_{1} e^{\lambda_{1} x_{e}}+\mathrm{C}_{2} e^{-\lambda_{1} x_{e}} \\
-\mathrm{C}_{\mathrm{e}}\end{array}$ & $\begin{array}{l}\delta\left(x_{e}=0\right)=0 \\
\delta\left(x_{e}=L_{t r}^{e}\right)=\delta_{i}\end{array}$ & $\begin{aligned} \text { Eq. (B1): } & C_{1}=\frac{\left(\delta_{i}+C_{e}\right)-C_{e} e^{-\lambda_{1} L_{t r}^{e}}}{2 \sinh \left(\lambda_{1} L_{t r}^{e}\right)} \\
C_{2} & =C_{e}-C_{1}\end{aligned}$ & - & $\begin{array}{l}\text { Eq. (A1): } L_{t r}^{e}=L_{b} \\
\text { Eq. (A2): } \varepsilon_{r}^{m}=\lambda_{1}\left(C_{1}-C_{2}\right) \\
\text { Eq. (A3): } \varepsilon_{r}^{c r}=\mathrm{C}_{1} e^{\lambda_{1} L_{t r}^{e}}+\mathrm{C}_{2} e^{-\lambda_{1} L_{t r}^{e}}-\mathrm{C}_{\mathrm{e}}\end{array}$ \\
\hline \multirow{2}{*}{2} & $\begin{array}{r}\mathrm{C}_{1} e^{\lambda_{1} x_{e}}+\mathrm{C}_{2} e^{-\lambda_{1} x_{e}} \\
-\mathrm{C}_{\mathrm{e}}\end{array}$ & $\begin{array}{l}\delta\left(x_{e}=0\right)=0 \\
\delta\left(x_{e}=L_{t r}^{e}\right)=\delta_{1}\end{array}$ & $\begin{array}{c}\text { Eq. (B2): } C_{1}=\frac{\left(\delta_{1}+C_{e}\right)-C_{e} e^{-\lambda_{1} L_{t r}^{e}}}{2 \sinh \left(\lambda_{1} L_{t r}^{e}\right)} \\
C_{2}=C_{e}-C_{1}\end{array}$ & \multirow{2}{*}{$\frac{d \delta}{d x_{e}}\left(x_{e}=L_{t r}^{e}\right)=\frac{d \delta}{d x_{h}}\left(x_{h}=0\right)$} & \multirow{2}{*}{$\begin{array}{l}\text { Eq. (A2): } \varepsilon_{r}^{m}=\lambda_{1}\left(C_{1}-C_{2}\right) \\
\text { Eq. (A4): } L_{t r}^{h}=L_{b}-L_{t r}^{e} \\
\text { Eq. (A5): } \\
\delta_{i}=A \sinh \left(\lambda_{2} L_{t r}^{h}\right)+C_{h} \cosh \left(\lambda_{2} L_{t r}^{h}\right)+\delta_{1}-C_{h} \\
\text { where } A=\frac{\lambda_{1}}{\lambda_{2}}\left(\mathrm{C}_{1} e^{\lambda_{1} L_{t r}^{e}}-\mathrm{C}_{2} e^{-\lambda_{1} L_{t r}^{e}}\right) \\
\text { Eq. (A6): } \varepsilon_{r}^{c r}=\mathrm{C}_{3} e^{\lambda_{2} L_{t r}^{h}}+\mathrm{C}_{4} e^{-\lambda_{2} L_{t r}^{h}}-\mathrm{C}_{h}+\delta_{1}\end{array}$} \\
\hline & $\begin{aligned} \mathrm{C}_{3} e^{\lambda_{2} x_{h}}+ & \mathrm{C}_{4} e^{-\lambda_{2} x_{h}} \\
& -\mathrm{C}_{h}+\delta_{1}\end{aligned}$ & $\begin{array}{l}\delta\left(x_{h}=0\right)=\delta_{1} \\
\delta\left(x_{h}=L_{t r}^{h}\right)=\delta_{i}\end{array}$ & 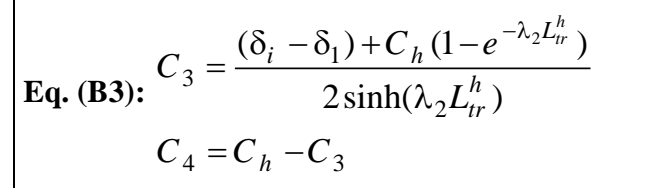 & & \\
\hline \multirow{3}{*}{3} & $\begin{array}{r}\mathrm{C}_{1} e^{\lambda_{1} x_{e}}+\mathrm{C}_{2} e^{-\lambda_{1} x_{e}} \\
-\mathrm{C}_{\mathrm{e}}\end{array}$ & $\begin{array}{l}\delta\left(x_{e}=0\right)=0 \\
\delta\left(x_{e}=L_{t r}^{e}\right)=\delta_{1}\end{array}$ & Eq. (B2): $\begin{aligned} C_{1} & =\frac{\left(\delta_{1}+C_{e}\right)-C_{e} e^{-\lambda_{1} L_{t r}^{e}}}{2 \sinh \left(\lambda_{1} L_{t r}^{e}\right)} \\
C_{2} & =C_{e}-C_{1}\end{aligned}$ & \multirow{3}{*}{$\begin{array}{l}\frac{d \delta}{d x_{e}}\left(x_{e}=L_{t r}^{e}\right)=\frac{d \delta}{d x_{h}}\left(x_{h}=0\right) \\
\frac{d \delta}{d x_{h}}\left(x_{h}=L_{t r}^{h}\right)=\frac{d \delta}{d x_{p}}\left(x_{p}=0\right)\end{array}$} & \multirow{3}{*}{$\begin{array}{l}\text { Eq. (A2): } \varepsilon_{r}^{m}=\lambda_{1}\left(C_{1}-C_{2}\right) \\
\text { Eq. (A7): } \\
A \sinh \left(\lambda_{2} L_{t r}^{h}\right)+C_{h} \cosh \left(\lambda_{2} L_{t r}^{h}\right)=\left(\delta_{2}-\delta_{1}\right)+C_{h} \\
\text { where } A=\frac{\lambda_{1}}{\lambda_{2}}\left(C_{1} e^{\lambda_{1} L_{t r}^{e}}-C_{2} e^{-\lambda_{1} L_{t r}^{e}}\right) \\
\text { Eq. (A8): } L_{t r}^{p}=L_{b}-L_{t r}^{e}-L_{t r}^{h} \\
\text { Eq. (A9): } \delta_{i}=C_{p}\left(L_{t r}^{p}\right)^{2}+B \cdot L_{t r}^{p}+\delta_{2} \\
\text { where } B=\lambda_{2}\left(C_{3} e^{\lambda_{2} L_{t r}^{h}}-C_{4} e^{-\lambda_{2} L_{t r}^{h}}\right) \\
\text { Eq. (A10): } \varepsilon_{r}^{c r}=C_{p}\left(L_{t r}^{p}\right)^{2}+C_{5} L_{t r}^{p}+C_{6}\end{array}$} \\
\hline & $\begin{aligned} \mathrm{C}_{3} e^{\lambda_{2} x_{h}}+ & \mathrm{C}_{4} e^{-\lambda_{2} x_{h}} \\
& -\mathrm{C}_{h}+\delta_{1}\end{aligned}$ & $\begin{array}{l}\delta\left(x_{h}=0\right)=\delta_{1} \\
\delta\left(x_{h}=L_{t r}^{h}\right)=\delta_{2}\end{array}$ & 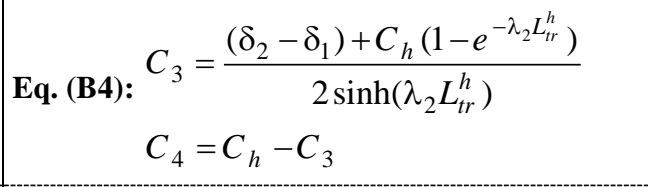 & & \\
\hline & $C_{p} x_{p}^{2}+C_{5} x_{p}+C_{6}$ & $\begin{array}{l}\delta\left(x_{p}=0\right)=\delta_{2} \\
\delta\left(x_{p}=L_{t r}^{p}\right)=\delta_{i}\end{array}$ & 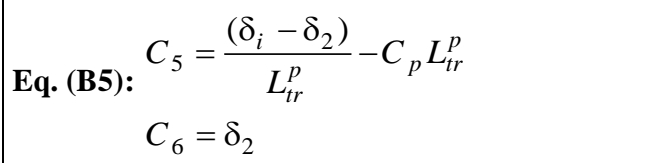 & & \\
\hline
\end{tabular}




\begin{tabular}{|c|c|c|c|c|c|}
\hline & $\begin{array}{r}\text { Slip functions } \delta(x) \\
\Rightarrow\end{array}$ & $\begin{array}{l}\text { Boundary } \\
\text { conditions }\end{array}$ & Slip solutions & Compatibility conditions & $\begin{array}{l}\text { Equations derived by considering compatibility } \\
\text { conditions }\end{array}$ \\
\hline \multirow{4}{*}{4} & $\begin{array}{r}\mathrm{C}_{1} e^{\lambda_{1} x_{e}}+\mathrm{C}_{2} e^{-\lambda_{1} x_{e}} \\
-\mathrm{C}_{\mathrm{e}}\end{array}$ & $\begin{array}{l}\delta\left(x_{e}=0\right)=0 \\
\delta\left(x_{e}=L_{t r}^{e}\right)=\delta_{1}\end{array}$ & 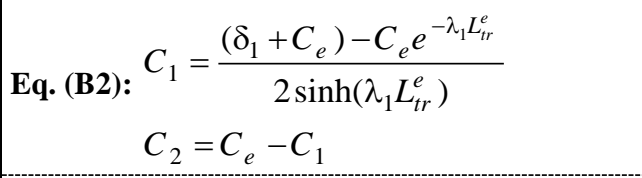 & \multirow{4}{*}{$\begin{array}{l}\frac{d \delta}{d x_{e}}\left(x_{e}=L_{t r}^{e}\right)=\frac{d \delta}{d x_{h}}\left(x_{h}=0\right) \\
\frac{d \delta}{d x_{h}}\left(x_{h}=L_{t r}^{h}\right)=\frac{d \delta}{d x_{p}}\left(x_{p}=0\right) \\
\frac{d \delta}{d x_{p}}\left(x_{p}=L_{t r}^{p}\right)=\frac{d \delta}{d x_{s o}}\left(x_{s o}=0\right)\end{array}$} & \multirow{4}{*}{$\begin{array}{l}\text { Eq. (A2): } \varepsilon_{r}^{m}=\lambda_{1}\left(C_{1}-C_{2}\right) \\
\text { Eq. (A7): } \\
A \sinh \left(\lambda_{2} L_{t r}^{h}\right)+C_{h} \cosh \left(\lambda_{2} L_{t r}^{h}\right)=\left(\delta_{2}-\delta_{1}\right)+C_{h} \\
\text { where } A=\frac{\lambda_{1}}{\lambda_{2}}\left(C_{1} e^{\lambda_{1} L_{t r}^{e}}-C_{2} e^{-\lambda_{1} L_{t r}^{e}}\right) \\
\text { Eq. (A11): } C_{p}\left(L_{t r}^{p}\right)^{2}+B \cdot L_{t r}^{p}=\left(\delta_{3}-\delta_{2}\right) \\
\text { where } B=\lambda_{2}\left(C_{3} e^{\lambda_{2} L_{t r}^{h}}-C_{4} e^{-\lambda_{2} L_{t r}^{h}}\right) \\
\text { Eq. (A12): } L_{t r}^{s o}=L_{b}-L_{t r}^{e}-L_{t r}^{h}-L_{t r}^{p} \\
\text { Eq. (A13): } \\
\delta_{i}=C \cdot \sin \left(\gamma L_{t r}^{s}\right)-C_{s o} \cos \left(\gamma L_{t r}^{s}\right)+\delta_{3}-C_{s o} \\
\text { where } C=\frac{1}{\gamma}\left(C_{5}+2 C_{p} L_{t r}^{p}\right) \\
\text { Eq. (A14): } \varepsilon_{r}^{c r}=C_{7} \sin \left(\gamma L_{t r}^{s o}\right)+C_{8} \cos \left(\gamma L_{t r}^{s o}\right)+C_{s o}+\delta_{3}\end{array}$} \\
\hline & $\begin{aligned} \mathrm{C}_{3} e^{\lambda_{2} x_{h}}+ & \mathrm{C}_{4} e^{-\lambda_{2} x_{h}} \\
& -\mathrm{C}_{h}+\delta_{1}\end{aligned}$ & $\begin{array}{l}\delta\left(x_{h}=0\right)=\delta_{1} \\
\delta\left(x_{h}=L_{t r}^{h}\right)=\delta_{2}\end{array}$ & Eq. (B4): $\begin{aligned} C_{3} & =\frac{\left(\delta_{2}-\delta_{1}\right)+C_{h}\left(1-e^{-\lambda_{2} L_{t r}^{h}}\right)}{2 \sinh \left(\lambda_{2} L_{t r}^{h}\right)} \\
C_{4} & =C_{h}-C_{3}\end{aligned}$ & & \\
\hline & $C_{p} x_{p}^{2}+C_{5} x_{p}+C_{6}$ & $\begin{array}{l}\delta\left(x_{p}=0\right)=\delta_{2} \\
\delta\left(x_{p}=L_{t r}^{p}\right)=\delta_{3}\end{array}$ & Eq. (B6): $\begin{aligned} C_{5} & =\frac{\left(\delta_{3}-\delta_{2}\right)}{L_{t r}^{p}}-C_{p} L_{t r}^{p} \\
C_{6} & =\delta_{2}\end{aligned}$ & & \\
\hline & $\begin{array}{l}C_{7} \sin \left(\gamma x_{s o}\right)+ \\
C_{8} \cos \left(\gamma x_{s o}\right)+ \\
+C_{s o}+\delta_{3}\end{array}$ & $\begin{array}{l}\delta\left(x_{s o}=0\right)=\delta_{3} \\
\delta\left(x_{s o}=L_{t r}^{s}\right)=\delta_{i}\end{array}$ & Eq. (B7): $\begin{aligned} C_{7} & =\frac{\left(\delta_{i}-\delta_{3}\right)-C_{s o}\left(\cos \left(\gamma L_{t r}^{s}\right)-1\right)}{\sin \left(\gamma L_{t r}^{s}\right)} \\
C_{8} & =-C_{s o}\end{aligned}$ & & \\
\hline \multirow{5}{*}{5} & $\begin{array}{r}\mathrm{C}_{1} e^{\lambda_{1} x_{e}}+\mathrm{C}_{2} e^{-\lambda_{1} x_{e}} \\
-\mathrm{C}_{\mathrm{e}}\end{array}$ & $\begin{array}{l}\delta\left(x_{e}=0\right)=0 \\
\delta\left(x_{e}=L_{t r}^{e}\right)=\delta_{1}\end{array}$ & Eq. (B2): $\begin{aligned} C_{1} & =\frac{\left(\delta_{1}+C_{e}\right)-C_{e} e^{-\lambda_{1} L_{t r}^{e}}}{2 \sinh \left(\lambda_{1} L_{t r}^{e}\right)} \\
C_{2} & =C_{e}-C_{1}\end{aligned}$ & \multirow{5}{*}{$\begin{array}{l}\frac{d \delta}{d x_{e}}\left(x_{e}=L_{t r}^{e}\right)=\frac{d \delta}{d x_{h}}\left(x_{h}=0\right) \\
\frac{d \delta}{d x_{h}}\left(x_{h}=L_{t r}^{h}\right)=\frac{d \delta}{d x_{p}}\left(x_{p}=0\right) \\
\frac{d \delta}{d x_{p}}\left(x_{p}=L_{t r}^{p}\right)=\frac{d \delta}{d x_{s o}}\left(x_{s o}=0\right) \\
\frac{d \delta}{d x_{s o}}\left(x_{s o}=L_{t r}^{s o}\right)=\frac{d \delta}{d x_{f}}\left(x_{f}=0\right)\end{array}$} & \multirow{5}{*}{$\begin{array}{l}\text { Eq. (A2): } \varepsilon_{r}^{m}=\lambda_{1}\left(C_{1}-C_{2}\right) \\
\text { Eq. (A7): } \\
A \sinh \left(\lambda_{2} L_{t r}^{h}\right)+C_{h} \cosh \left(\lambda_{2} L_{t r}^{h}\right)=\left(\delta_{2}-\delta_{1}\right)+C_{h} \\
\text { where } A=\frac{\lambda_{1}}{\lambda_{2}}\left(C_{1} e^{\lambda_{1} L_{t r}^{e}}-C_{2} e^{-\lambda_{1} L_{t r}^{e}}\right) \\
\text { Eq. (A11): } C_{p}\left(L_{t r}^{p}\right)^{2}+B \cdot L_{t r}^{p}=\left(\delta_{3}-\delta_{2}\right) \\
\text { where } B=\lambda_{2}\left(C_{3} e^{\lambda_{2} L_{t r}^{h}}-C_{4} e^{-\lambda_{2} L_{t r}^{h}}\right) \\
\text { Eq. (A15): } \\
C \cdot \sin \left(\gamma L_{t r}^{s o}\right)-C_{s o} \cos \left(\gamma L_{t r}^{s o}\right)=\left(\delta_{4}-\delta_{3}\right)+C_{s o} \\
\text { where } C=\frac{1}{\gamma}\left(C_{5}+2 C_{p} L_{t r}^{p}\right) \\
\text { Eq. (A16): } L_{t r}^{f}=L_{b}-L_{t r}^{e}-L_{t r}^{h}-L_{t r}^{p}-L_{t r}^{s o} \\
\text { Eq. (A17): } \delta_{i}=C_{f}\left(L_{t r}^{f}\right)^{2}+D \cdot L_{t r}^{f}+\delta_{4} \\
\text { where } D=\gamma\left(C_{7} \cos \left(\gamma L_{t r}^{s o}\right)-C_{8} \sin \left(\gamma L_{t r}^{s o}\right)\right) \\
\text { Eq. (A18): } \varepsilon_{r}^{c r}=C_{f}\left(L_{t r}^{f}\right)^{2}+C_{9} L_{t r}^{f}+C_{10}\end{array}$} \\
\hline & $\begin{aligned} \mathrm{C}_{3} e^{\lambda_{2} x_{h}}+ & \mathrm{C}_{4} e^{-\lambda_{2} x_{h}} \\
& -\mathrm{C}_{h}+\delta_{1}\end{aligned}$ & $\begin{array}{l}\delta\left(x_{h}=0\right)=\delta_{1} \\
\delta\left(x_{h}=L_{t r}^{h}\right)=\delta_{2}\end{array}$ & Eq. (B4): $\begin{aligned} C_{3} & =\frac{\left(\delta_{2}-\delta_{1}\right)+C_{h}\left(1-e^{-\lambda_{2} L_{t r}^{h}}\right)}{2 \sinh \left(\lambda_{2} L_{t r}^{h}\right)} \\
C_{4} & =C_{h}-C_{3}\end{aligned}$ & & \\
\hline & $C_{p} x_{p}^{2}+C_{5} x_{p}+C_{6}$ & $\begin{array}{l}\delta\left(x_{p}=0\right)=\delta_{2} \\
\delta\left(x_{p}=L_{t r}^{p}\right)=\delta_{3}\end{array}$ & Eq. (B6): $\begin{aligned} C_{5} & =\frac{\left(\delta_{3}-\delta_{2}\right)}{L_{t r}^{p}}-C_{p} L_{t r}^{p} \\
C_{6} & =\delta_{2}\end{aligned}$ & & \\
\hline & $\begin{array}{r}C_{7} \sin \left(\gamma x_{s o}\right)+ \\
C_{8} \cos \left(\gamma x_{s o}\right)+ \\
+C_{s o}+\delta_{3}\end{array}$ & $\begin{array}{l}\delta\left(x_{s o}=0\right)=\delta_{3} \\
\delta\left(x_{s o}=L_{t r}^{s o}\right)=\delta_{4}\end{array}$ & Eq. (B8): $\begin{aligned} C_{7} & =\frac{\left(\delta_{4}-\delta_{3}\right)-C_{s o}\left(\cos \left(\gamma L_{t r}^{s o}\right)-1\right)}{\sin \left(\gamma L_{t r}^{s o}\right)} \\
C_{8} & =-C_{s o}\end{aligned}$ & & \\
\hline & $C_{f} x_{f}^{2}+C_{9} x_{f}+C_{10}$ & $\begin{array}{l}\delta\left(x_{f}=0\right)=\delta_{4} \\
\delta\left(x_{f}=L_{t r}^{f}\right)=\delta_{i}\end{array}$ & 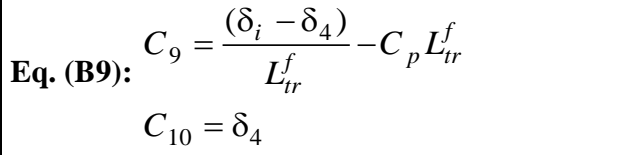 & & \\
\hline
\end{tabular}




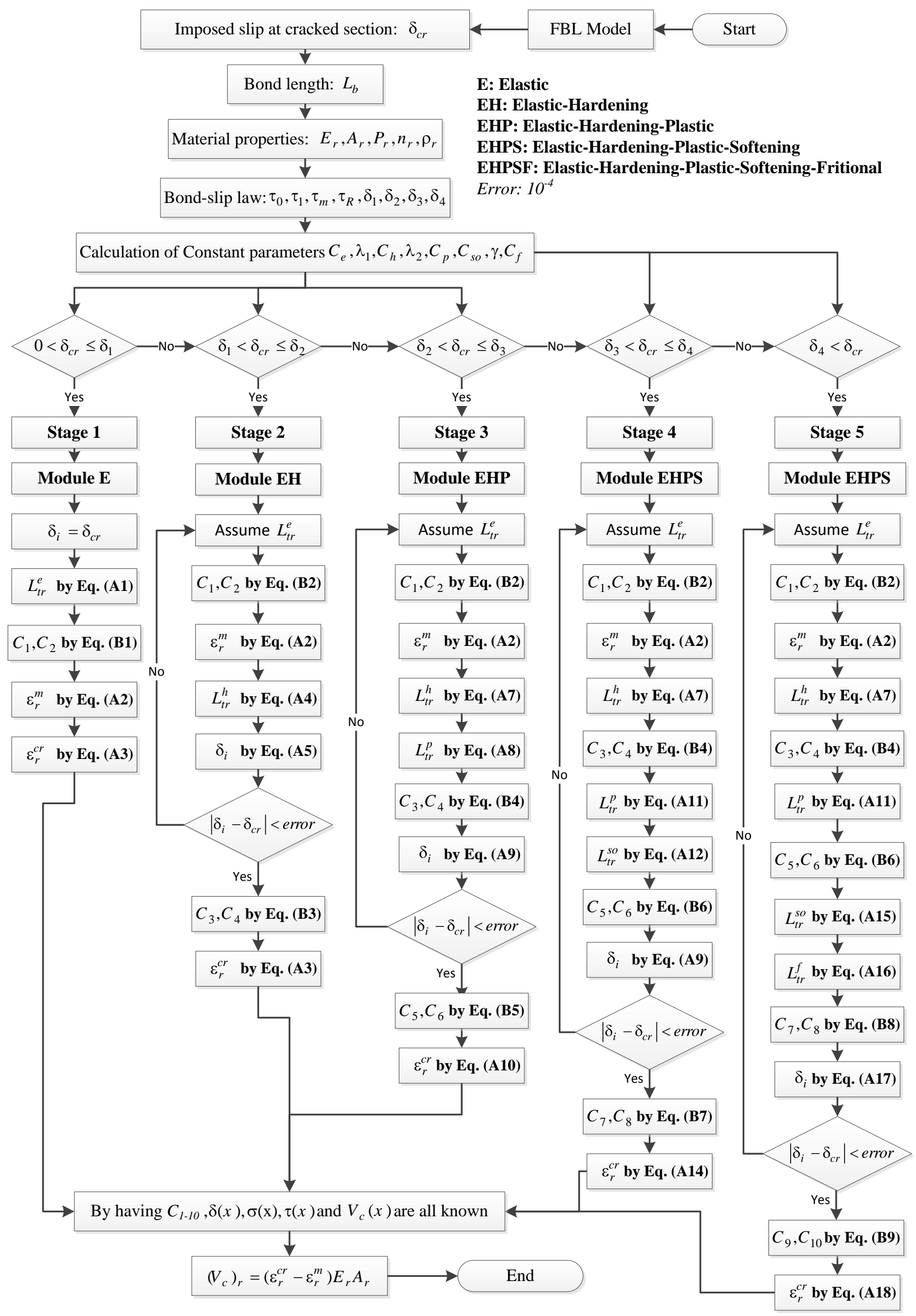

Figure A.1.Algorithm of FBL model 

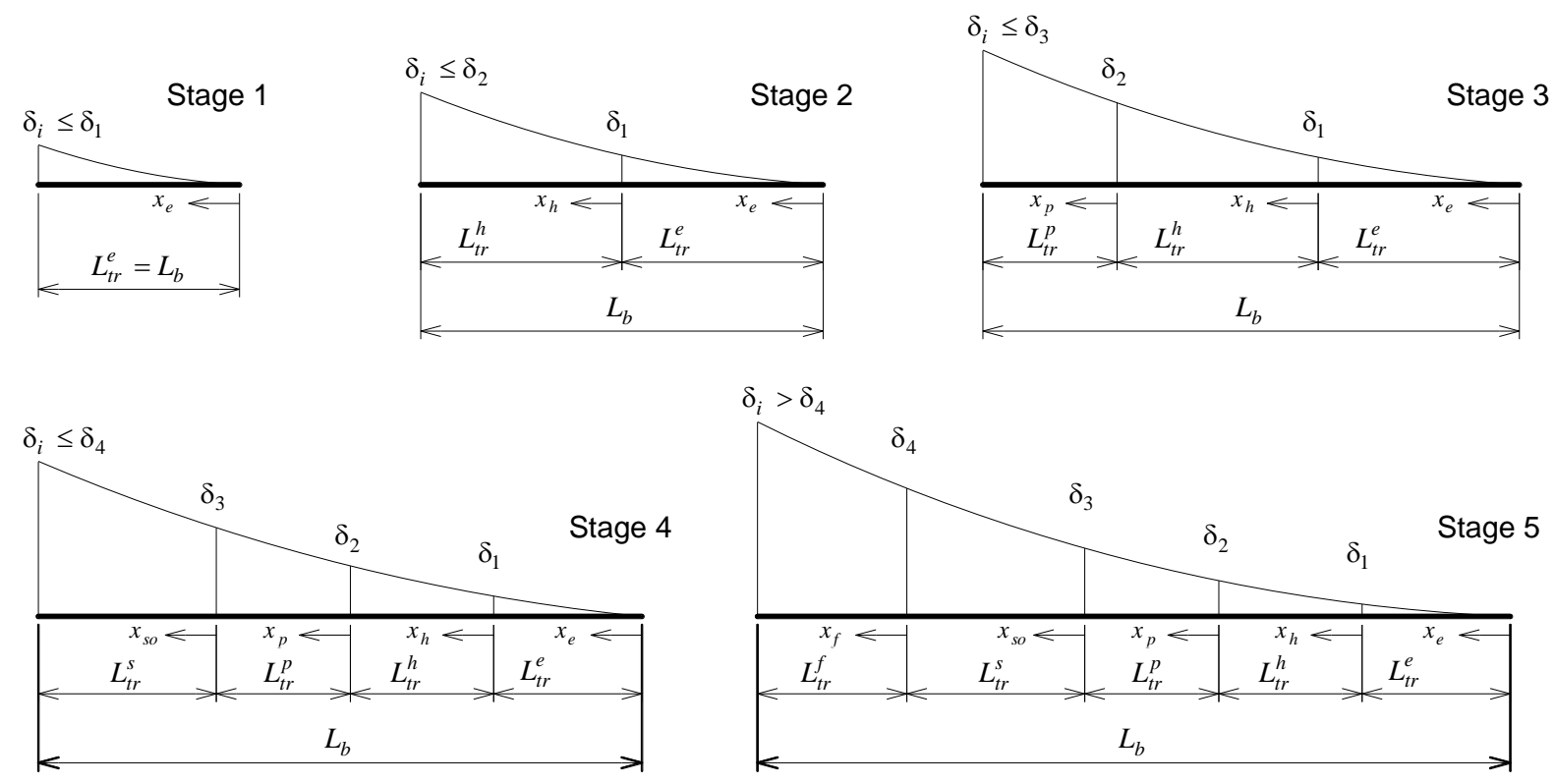

Figure A.2.Schematic definition of $x_{e}, x_{h}, x_{p}, x_{s o}$ and $x_{f}$, as well as $L_{t r}^{e}, L_{t r}^{h}, L_{t r}^{p}, L_{t r}^{s o}$ and $L_{t r}^{f}$ (not to scale). 